\title{
Review of phenotypic assays for detection of extended-spectrum $\beta$-lactamases and carbapenemases: a microbiology laboratory bench guide
}

\author{
Dickson Aruhomukama
}

\begin{abstract}
Department of Medical Microbiology, College of Health Sciences, Makerere University, Kampala, Uganda.
\end{abstract}
\begin{abstract}
Background: Infections caused by gram-negative antibiotic-resistant bacteria continue to increase. Despite recommendations by the Clinical Laboratory Standards Institute (CLSI) and the European Committee on Antimicrobial Susceptibility Testing (EUCAST) with regards to detection of antibiotic degrading enzymes secreted by these bacteria, the true prevalence of extended-spectrum $\beta$-lactamase (ESBL) and carbapenemase producers remains a difficult task to resolve. Describing of previously designed phenotypic detection assays for ESBLs and carbapenemases in a single document avails a summary that allows for multiple testing which increases the sensitivity and specificity of detection.

Methods and aims: This review, therefore, defined and classified ESBLs and carbapenemases, and also briefly described how the several previously designed phenotypic detection assays for the same should be performed.

Conclusion: Extended-spectrum $\beta$-lactamase and carbapenemase detection assays, once performed correctly, can precisely discriminate between bacteria producing these enzymes and those with other mechanisms of resistance to $\beta$-lactam antibiotics.

Keywords: Extended-spectrum $\beta$-lactamases; carbapenemases; phenotypic detection.

DOI: https://dx.doi.org/10.4314/ahs.v20i3.11

Cite as: Aruhomukama D. Review of phenotypic assays for detection of extended-spectrum $\beta$-lactamases and carbapenemases: a microbiology laboratory bench guide. Afri Health Sci.. 2020;20(3): 1090-1108. https:/ / dx.doi.org/10.4314/ abs.v20i3.11
\end{abstract}

\section{Introduction}

Infections involving extended-spectrum $\beta$-lactamase and carbapenemase producing gram-negative bacteria continue to increase in health-care settings ${ }^{1,2}$. These infections remain difficult to treat and are a serious public health concern ${ }^{1,2}$. This is because, even the most likely non-fatal infections become fatal when they involve these antibiotic resistant bacteria ${ }^{2}$. Extended-spectrum $\beta$-lactamase and carbapenemase enzymes hydrolyze and hence inactivate $\beta$-lactam antibiotics resulting in $\beta$-lactam resistance in bacteria that are producers of these enzymes ${ }^{3}$. Increased $\beta$-lactam resistance in bacteria is due to their continuous exposure to $\beta$-lactam antibiotics, this has contributed to increased uninterrupted production and mutation of $\beta$-lactamases in

\section{Corresponding author: \\ Dickson Aruhomukama, \\ Department of Medical Microbiology, \\ College of Health Sciences, \\ Makerere University, Kampala, Uganda. \\ Tel; +256706511287 \\ Email: dickson.aruhomukama@chs.mak.ac.ug}

bacteria $^{1,4}$. The true prevalence of ESBL and carbapenemase producing bacteria remains a difficult task to resolve despite the recommendations provided by CLSI and EUCAST for detection of these enzymes ${ }^{1,5-8}$. This is due to among others, incompetence of most clinical microbiology laboratory staff to correctly perform the phenotypic detection assays and report production of these enzymes ${ }^{1,5-7}$. This suggests that improvements in competence of clinical microbiology laboratory staff to correctly perform the assays and report production of these enzymes are needed ${ }^{1,5-7}$. The correct performance of these assays is beneficial in distinguishing between bacteria producing $\beta$-lactamases and those with other mechanisms of resistance to $\beta$-lactam antibiotics. Additionally, correct performance of these assays is vital in reducing the need to apply the more expensive molecular techniques used in detecting production of these enzymes. Hence, this review defines and classifies ESBLs and carbapenemases, and summarizes the several previously designed phenotypic assays used to detect production of these enzymes in gram-negative antibiotic resistant bacteria.

Extended-spectrum $\beta$-lactamases: Definition and classification 
Extended-spectrum $\beta$-lactamases are enzymes that break down and thus inactivate $\beta$-lactam antibiotics ${ }^{1,3,9,10}$. Additionally, ESBLs are characterized by their susceptibility to inhibition by $\beta$-lactam inhibitors particularly; clavulanic acid (CA), tazobactam and sulbactam ${ }^{1,3,9}$. $\beta$-lactamases are classified according to two schemes, these are; i) the Bush Jacoby-Medeiros functional classification and ii) the Ambler molecular classification ${ }^{1,3,9}$. The basis of the Bush-Jacoby-Medeiros functional classification is the functional properties of the $\beta$-lactamase enzymes principally, their inhibitor and substrate profiles $^{3,9}$. The Ambler molecular classification however is based on the protein homology of the $\beta$-lactamase enzymes $^{3,9}$. The Ambler molecular classification further classifies $\beta$-lactamase enzymes into four classes namely; class $A, C$ and $D$ also known as the Serine $\beta$-lactamases and class $B \beta$-lactamases also known as the zinc or metallo $\beta$-lactamases ${ }^{3,9}$.

The CTX-M type forms the most common genetic variant of ESBLs ${ }^{1,9,11-14}$. This family of $\beta$-lactamases specially hydrolyze cefotaxime (CTX) over ceftazidime (CAZ) and are found exclusively in the functional group $2^{1,9,11-}$ ${ }^{14}$. Also, unique to these $\beta$-lactamases is their susceptibility to inhibition by the $\beta$-lactam inhibitor tazobactam as compared to inhibition by the other $\beta$-lactam inhibitors, CA and sulbactam ${ }^{1,12,15}$. The extended-spectrum of activity of the CTX-M $\beta$-lactamases is due to the serine residue present at position $237^{1,11}$. The CTX-M $\beta$-lactamases are divided into five groups namely; the CTX-M group 1, 2, 8, 9 and 25 basing on their amino acid sequences ${ }^{1,9,16}$. Unlike the other $\beta$-lactamase enzymes, the CTX-M enzymes are acquired and disseminated in bacteria via mobile genetic elements particularly conjugative plasmids and transposons in horizontal gene transfer processes ${ }^{1}$. The TEM type $\beta$-lactamases form another $\beta$-lactamase family; $\beta$-lactamases belonging to the TEM type, TEM-1 a variant of TEM hydrolyze penicillins and first-generation cephalosporins ${ }^{1}$. The TEM-3 $\beta$-lactamases, which are another variant of TEM $\beta$-lactamases hydrolyze extended-spectrum cephalosporins ${ }^{1,17,18}$. In addition to these families is the SHV type $\beta$-lactamases, SHV-1 $\beta$-lactamases, a variant of the SHV hydrolyze broad spectrum penicillins, these include ampicillin, tigecycline and piperacillin ${ }^{18,19}$; the OXA type $\beta$-lactamases, these $\beta$-lactamases exhibit the ability to hydrolyze oxacillin, are predominantly present in Pseudomonas aeruginosa and Acinetobacter baumannii however also occur in other gram-negative bacteria ${ }^{1,9,20,21}$; the PER type $\beta$-lactamases, unique about these $\beta$-lacta- mases is their efficient hydrolysis of penicillins, cephalosporins and their susceptibility to CA inhibition ${ }^{1,3,9}$; the GES type $\beta$-lactamases, these $\beta$-lactamases hydrolyze penicillins and extended-spectrum cephalosporins, but not cephamycins or carbapenems, these are also inhibited by $\beta$-lactamase inhibitors ${ }^{1,3,9}$; other described $\beta$-lactamase families include among others the VEB-1, BES1, CME-1 and SFO-1, enzymes belonging to these families have mostly been found to exhibit $\beta$-lactamase activity $^{1,22,23}$.

\section{Carbapenemases: Definition and classification}

Carbapenemases are enzymes that break down and thus inactivate carbapenem antibiotics; these enzymes represent the most versatile family of $\beta$-lactamases and are uniquely characterized by their broad spectrum of activity as compared to other $\beta$-lactam hydrolyzing enzymes $^{3,9,24-28}$. Carbapenemases are classified into two major groups basing on the nature of their active sites, these groups are: the serine carbapenemases belonging to the class A penicillinases and class $\mathrm{D}$ oxacillinases and the metallo $\beta$-lactamases belonging to the class $\mathrm{B}$ carbapenemases which contain one or more zinc atoms at their active sites a characteristic future that allows them to hydrolyze the bicyclic $\beta$-lactam ring ${ }^{3,9,24-28}$.

Class A carbapenemases, also known as the class A serine carbapenemases, when present in bacteria confer a characteristic reduced susceptibility to imipenem ${ }^{24,28}$. Class A carbapenemases include; IMI/NMC, KPC, GES and SME enzymes ${ }^{24,28}$. These enzymes need an active serine at position 70 for their hydrolytic activity in the Ambler numbering system for class A $\beta$-lactamases, hydrolyze carbapenems, cephalosporins, penicillins and aztreonam, are inhibited by CA and tazobactam ${ }^{24,28,29}$. IMI, NMC and SME are chromosomally encoded enzymes whereas GES and KPC enzymes are plasmid en$\operatorname{coded}^{24,28}$.

Class B carbapenemases, also known as class B metallo $\beta$-lactamases hydrolytic activity is dependent on the interaction of the $\beta$-lactams with zinc ions in the active sites of these enzymes, these interactions result in the distinctive trait of their inhibition by EDTA which is a chelator of zinc and other divalent ions ${ }^{24,26,28,30,31}$. These enzymes ably hydrolyze carbapenems, are resistant to commercially available $\beta$-lactamase inhibitors, are susceptible to inhibition by metal ion chelators and have a relatively broad substrate profile that includes cephalosporins and penicillins $s^{24,26,28,30,31}$. Also, characteristic to the class B carbapenemases is their inability to hydrolyze 
aztreonam $24,26,28,30,31$. These enzymes include; GIM, IMP, VIM, NDM and SIM ${ }^{24,28,31}$. Additionally, these enzymes mostly occur in integron structures and are mostly disseminated via mobile genetic elements particularly conjugative plasmids and transposons in horizontal gene transfer ${ }^{24,28,31,32}$.

Class D carbapenemases, also known as class D Metallo $\beta$-lactamases or the OXA $\beta$-lactamases are uniquely characterized by their association with plasmids, hence are mostly plasmid encoded, although may also be chromosomally encoded ${ }^{9,24,28,33,34}$. Additionally, these enzymes hydrolyze oxacillin and cloxacillin, are penicillinases, are poorly inhibited by CA and EDTA, and have large amounts of variability in their amino acid sequences $9,24,28,34,35$.

\section{AmpC $\beta$-lactamases: Definition and classification}

AmpC $\beta$-lactamases are chromosomally encoded cephalosporinases that mediate resistance to most penicillins, cefoxitin, cefazolin, cephalothin, and $\beta$-lactamase inhibitor- $\beta$-lactam combinations ${ }^{36-38}$. These enzymes belong to class $\mathrm{C}$ in the Ambler molecular classification of $\beta$-lactamases, while they are assigned to group 1 in the Bush Jacoby-Medeiros functional classification scheme ${ }^{1,3,9}$. They mostly occur in the Enterobacteriaceae, however, they have also been reported to occur in a few non-Enterobacteriacea $e^{36,37}$. In most of these bacteria, AmpC $\beta$-lactamases are inducible and are expressed at high levels by mutation ${ }^{36}$. The over expression of these enzymes is reported to confer resistance to extended-spectrum cephalosporins that include: CTX, CAZ and ceftriaxone ${ }^{36}$. Evidence of induction of resistance in bacterial isolates belonging to Enterobacter spp. initially susceptible to these extended-spectrum cephalosporins upon therapy is available ${ }^{36-38}$. The prevalence of resistance mediated by plasmid-mediated AmpC $\beta$-lactamases has been shown to be low in most parts of the world as compared to the ESBLs, these have also been documented to be harder to detect as compared to ESBLs, and to mostly exhibit a broad-spectrum antibiotic activity $^{36,37}$. Current detection assays of these enzymes have been reported to lack specificity and/or sensitivity, they have also been reported to be inconvenient, subjective, and to require reagents mostly unavailable to many clinical microbiology laboratories ${ }^{37}$. In addition, recent times have witnessed identification of bacteria previously lacking and/or poorly expressing chromosomally-mediated AmpC genes as AmpC $\beta$-lactamases producers ${ }^{36-38}$. This has been possible through the acquisition of these genes via conjugative plasmids in horizontal gene transfer, a phenomenon typical- ly seen to occur in Escherichia coli, Klebsiella pneumoniae, and Proteus mirabilis ${ }^{36-38}$. Both chromosomally encoded and plasmid-mediated AmpC $\beta$-lactamases continue to evolve, through evolution, these attain potentials to hydrolyze extended-spectrum cephalosporins more efficiently $^{36-38}$. Just like the AmpC $\beta$-lactamases, phenotypic detection methods for the same continue to evolve, and are mostly not yet optimized for the clinical microbiology laboratory ${ }^{36-38}$.

\section{Phenotypic detection of extended-spectrum \\ $\beta$-lactamase production}

Disk diffusion and broth micro-dilution methods have been described to ably detect production of ESBLs in gram-negative bacteria ${ }^{5}$. However, currently some of these methods have become increasingly unreliable, this is due to: i) the co-existence of different classes of $\beta$-lactamases in gram-negative bacteria ${ }^{39-42}$, ii) difficulties recognizing ESBL production due to the over-expression of AmpC $\beta$-lactamases ${ }^{39-42}$, iii) potential masking of ESBL production by AmpC producing bacteria which serve as reservoirs of ESBLs ${ }^{39-42}$, and iv) the general inability of most clinical microbiology laboratory staff to ably perform testing for detection of ESBL production ${ }^{42-45}$. These affect testing and so result in inappropriate antimicrobial therapy ${ }^{39,46}$. In the testing for ESBL production, other factors including inoculum density $^{47-49}$ and the distance between the disks ${ }^{48-51}$ being tested influence the outcomes of the testing.

Testing for ESBL production in bacteria is a two stage process that involves screening and confirmation that follows testing bacteria against array of antibiotics namely: cefpodoxime, CAZ, CRO, CTX and aztreonam and identifying specific zone diameters indicative of potential ESBL production ${ }^{52,53}$. Testing with greater than one of the antibiotics is recommended to improve sensitivity of ESBL detection ${ }^{52,53}$. It is however recommended to use CTX, due to its consistent susceptibility to CTX-M and CAZ, due its consistent susceptibility to TEM and SHV ${ }^{52,54-56}$. Cefpodoxime should be used when testing using a single drug ${ }^{52,54-56}$. Reduced susceptibility to any of the agents as specified by CLSI is a qualification of ESBL testing and necessitates phenotypic confirmatory testing to confirm diagnosis ${ }^{53}$. Phenotypic confirmation of ESBL production is achieved using array of methods, including: the use of the cephalosporin/clavulanate combination disk diffusion or broth micro-dilution method ${ }^{52,53}$, use of DDS meth$\operatorname{od}^{5,51,52,57,58}$ and MDDS method which is a modification of the DDS method that confirms ESBL production 
and differentiates ESBL production and overexpression of AmpC-derepressed mutants ${ }^{51,53,57,58}$.

Double disk synergy (DDS) and modified double disk synergy (MDDS)

Both the DDS and MDDS are used in the detection of ESBL production in gram-negative bacteria ${ }^{48,51,57-59}$. In the DDS, testing is performed by inoculating Mueller-Hinton agar with a lawn culture of organisms for the standard diffusion method and placing onto the agar plate a commercially available disc of CTX $(30 \mu \mathrm{g})$

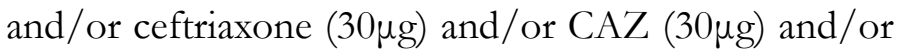

aztreonam $(30 \mu \mathrm{g})$ and a disc of amoxicillin-clavulanic acid $(20 / 10 \mu \mathrm{g})$ at a distance of $30 \mathrm{~mm}$ center to center as shown in figure $1^{5,51,56,57,60}$. However, narrower distances $(<30 \mathrm{~mm})$ between the discs is reported to increase the sensitivity of the test ${ }^{5,51,56,57,60}$. Interpretation of the results is done after incubation at $350 \mathrm{C} \pm 20 \mathrm{C}$ for 18-24 hrs as follows: a decreased susceptibility to the antibiotic disc used combined with a clear-cut enhancement of the inhibition zone of same antibiotic disc in front of the CA containing disc, often resulting in a characteristic shape-zone referred to as "champagne-cork" or key hole as seen in figure 1 is indicative of ESBL production $5,51,56,57,60$.

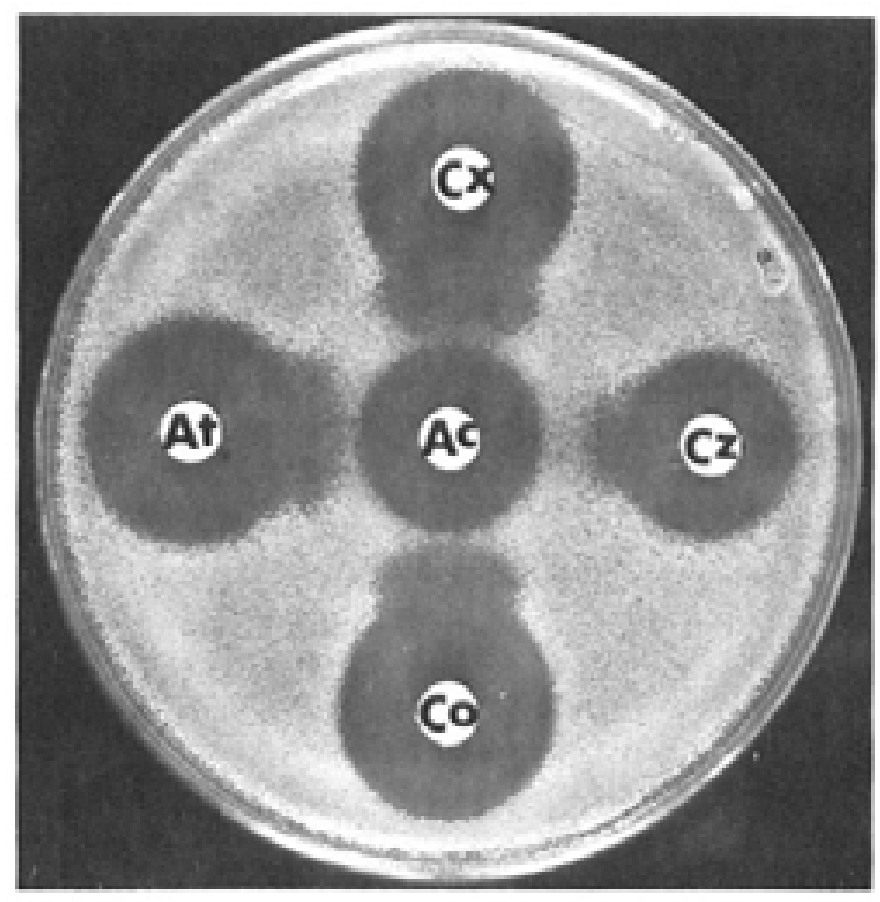

Fig .1. DDS. Photograph showing extension and broadening of inhibitory zones of the third generation cephalosporins towards the amoxicillin-clavulanic acid disc. Reprinted from the European Journal of Clinical Microbiology and Infectious Diseases (vol. 8, Issue 6, pp 527529), by Legrand, P., et al., 1989. Copyright 1989 by the European Journal of Clinical Microbiology and Infectious Diseases.

In the MDDS, the following antibiotic discs are used: amoxicillin-clavulanic acid $(20 / 10 \mu \mathrm{g})$ or piperacillin-tazobactam $(100 / 10 \mu \mathrm{g})$ along three third-generation cephalosporins: CAZ $(30 \mu \mathrm{g})$, ceftriaxone $(30 \mu \mathrm{g})$, and cefpodoxime $(30 \mu \mathrm{g})$ as well as a fourth-generation cephalosporin, cefepime $(30 \mu \mathrm{g})^{5,57}$. This test is performed by inoculating a lawn culture of organisms on Mueller-Hinton agar for the standard diffusion method and placing onto the agar plate a commercially available amoxicillin-clavulanic acid disc, preferentially in the center of the testing area ${ }^{5,51,57,60}$. The discs including the third and fourth-generation cephalosporins are then placed $15 \mathrm{~mm}$ and $20 \mathrm{~mm}$ respectively, center to center to that of the amoxicillin-clavulanic acid disc on the agar plate as shown in figure 2 and $3^{5,51,57,60}$. Interpretation of the results is done after incubation at $350 \mathrm{C} \pm$ 20C for 18-24 hrs in ambient air as follows: any distortion or increase in the zone towards the disc of amoxicillin-clavulanic acid is indicative of ESBL production as seen in figure 2 and $3^{5,51,57,60}$. In addition, strains are 
divided into three groups basing on the interpretation with MDDS and their susceptibilities to CTX and CAZ, these groups include: Group 1 (Wild type) that includes ESBL non-producers sensitive to CTX and CAZ, Group 2 (derepressed mutants) that includes ESBL non-producers resistant to CTX and CAZ, and Group

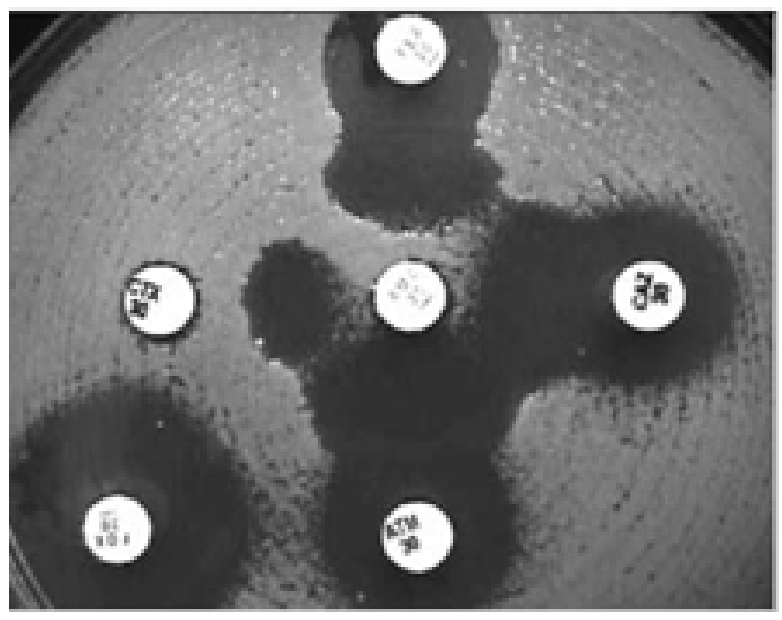

Fig. 2. MDDS. The organism shows an enhanced zone of inhibition between CAZ, CTX, cefepime, aztreonam, and amoxicillin-clavulanic acid (centre disc), indicating ESBL production. Reprinted from the British Journal of Biomedical Science (vol. 63.2 (2006): 51-54), by Kader, A. A., et al., 2006. Copyright 2006 by the British Journal of Biomedical Science.

This test can also be used to presumptively identify AmpC $\beta$-lactamase producing gram-negative bacteria $^{5,36,49,56}$. This is because, cefepime, the fourth-generation cephalosporin included in the testing is less rapidly inactivated by AmpC $\beta$-lactamases than by ES$\mathrm{BLs}^{5,36,49,56}$. Cefepime improves the detection of synergy with the amoxicillin-clavulanic acid in circumstances when simultaneous stable hyper-production of the AmpC $\beta$-lactamases occurs $5,36,49,56$.

\section{Three-dimensional tests (direct and indirect)}

The three-dimensional tests are also used in detection of ESBL production in gram-negative bacteria ${ }^{5,51,59,61}$. In the direct-three dimensional test, a $0.5 \mathrm{McF}$ arland of the test organisms is inoculated onto the surface of a Mueller-Hinton agar plate, this is then dispensed with inoculums between 109-1010 cells/ $\mathrm{ml}$ in a circular slit
3 (ESBL producers) includes ESBL producers sensitive, intermediate or resistant to CTX and CAZ ${ }^{5,57,58}$. Worth mentioning, reporting of results is as follows; isolates with a positive confirmatory test are reportd as resistant to all penicillins, cephalosporins and aztreonam except for cephamycins and cefoxitin irrespective of the MIC of the particular cephalosporin ${ }^{5,57,58}$.

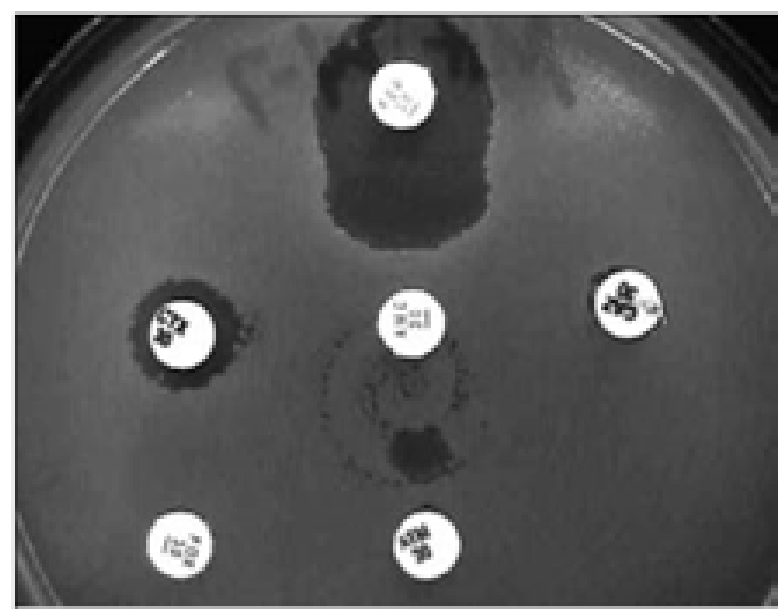

Fig. 3. MDDS. The organism shows resistance to CTX, CAZ, aztreonam and an enhanced zone of inhibition between cefepime (top disc) and amoxicillin-clavulanic acid (centre disc), indicating ESBL production and presumptive AmpC $\beta$ lactamase production. Reprinted from the British Journal of Biomedical Science (vol. 63.2 (2006): 51-54), by Kader, A. A., et al., 2006. Copyright 2006 by the British Journal of Biomedical Science.

cut in the agar so that the slit is filled ${ }^{5,51,59,61}$. Following this, antibiotic discs are placed on the agar plate, $3 \mathrm{~mm}$ outside the strain- containing slit as shown in figures 4, 5 and 6 5,51,59,61. By inspecting the margin of the inhibition zone in the vicinity of intersection with the strain containing slit, enzymatic inactivation of each antibiotic is then detected ${ }^{5,51,59,61}$. Interpretation of the test as positive is dependent on inactivation of the antibiotic as it diffuses through the slit resulting in a distortion or discontinuity in the expected circular inhibition zone, or production of discrete colonies in the vicinity of the inoculated slit ${ }^{5,51,59,61}$. The indirect three-dimensional test is a modification of the direct three dimensional test; in this test, the defining difference from the direct three dimensional test is that the surface of agar plate is inoculated with a fully susceptible indicator strain, E. coli ATCC $25922^{5,51,59,61}$. 

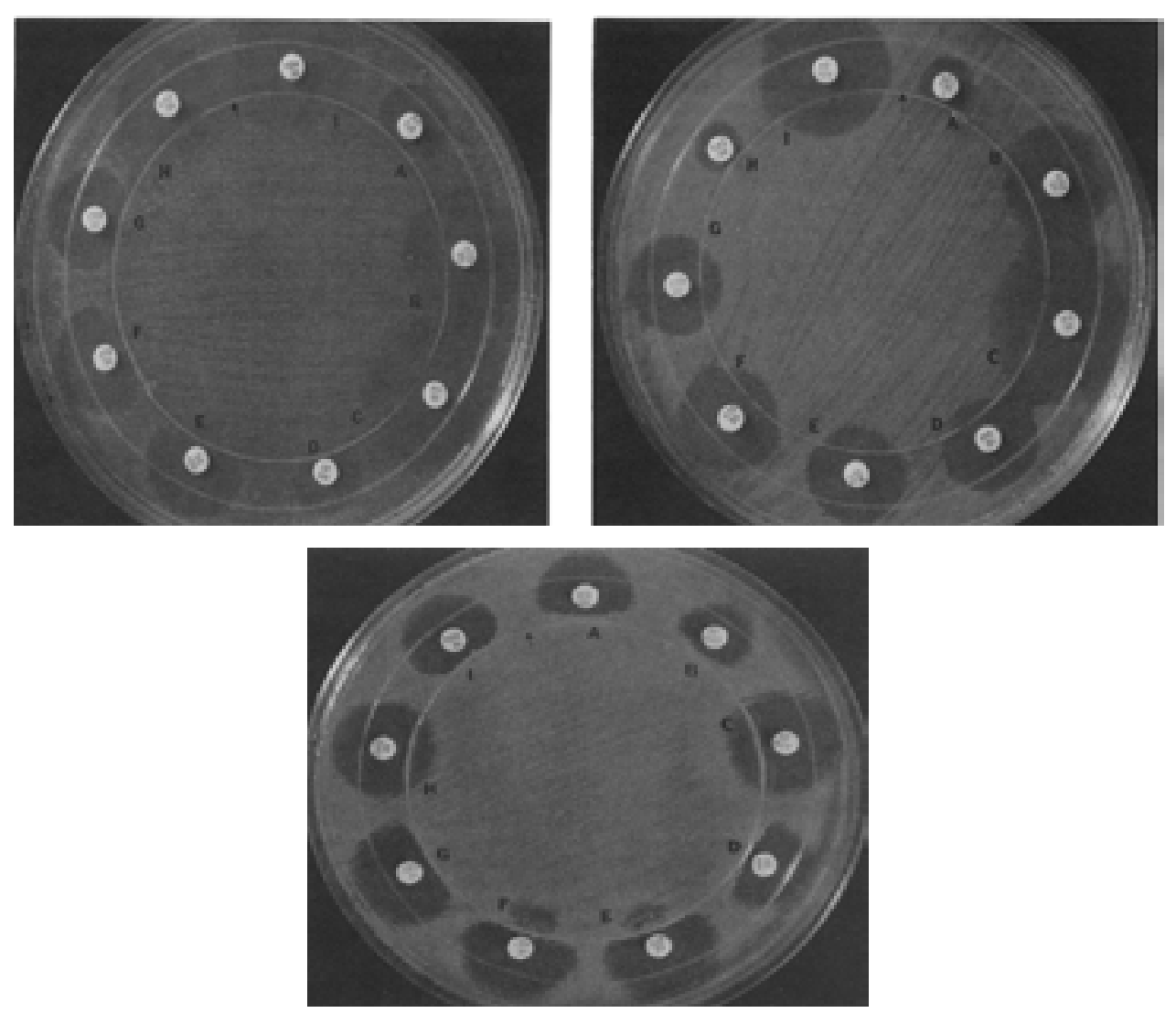

Fig. 4. The circular three-dimensional inoculation (indicated by the arrow) intersected the inhibition zone margins to produce major distortions (i.e., positive three-dimensional test results) that indicated enzymatic inactivation of piperacillin (A), cefamandole (D), cefoperazone (E), CTX (F), and ceftriaxone (G). Distortions did not occur (i.e., negative three-dimensional test results) in tests with aztreonam (B), imipenem (C), CAZ (H), or cefoxitin (I). The outer circle is the plastic rim on the bottom of the petri dish. Fig. 5. The three-dimensional inoculation (arrow) resulted in minor distortions that indicated antibiotic inactivation (i.e., positive three-dimensional test results) at the intersection with the zone margins of cefamandole (D), cefoperazone (E), CTX (F), and ceftriaxone (G). Distortions did not occur in tests with aztreonam (B), imipenem (C), or cefoxitin (I). The inhibition zones were too small to interpret in the direct three-dimensional test in tests with piperacillin (A) and CAZ (H). Fig. 6. Major zone distortions that indicated antibiotic inactivation (i.e., positive three dimensional test results) occurred in tests with piperacillin (A), cefuroxime (B), cefamandole (D), cefoperazone (E), CTX (F), ceftriaxone (G), and cefoxitin (I) but not in tests with aztreonam $(\mathrm{C})$ or CAZ $(\mathrm{H})$. Note the growth of small colonies in the cefoperazone (E) and CTX (F) zones in the vicinity of the three-dimensional inoculation site. The small colonies in this part of the zone also indicated enzymatic drug inactivation (i.e., positive three-dimensional test results). Reprinted from the Journal of Antimicrobial Agents and Chemotherapy (vol. 36, (9), pp.1877-1882), by Thomson, K.S. and Sanders, C.C., 1992. Copyright 1992 by the Journal of Antimicrobial Agents and Chemotherapy.

Bacterial producers of AmpC $\beta$-lactamases are susceptible to fourth-generation cephalosporins (cefepime and cefpirome $)^{36,41}$, and are poorly inhibited by $C A^{36,41}$. As a result, these are resistant to $\beta$-lactam $/ \beta$-lactamase-inhibitor combinations and give a positive and neg- ative test during ESBL screening and confirmation respectively ${ }^{62}$. These features form the basis of screening and confirmation of AmpC $\beta$-lactamase production in gram-negative bacteria ${ }^{36,62-64}$. Presumptive identification of AmpC $\beta$-lactamase producing Enterobacteriaceae can be achieved following the criteria in figure 7 . 


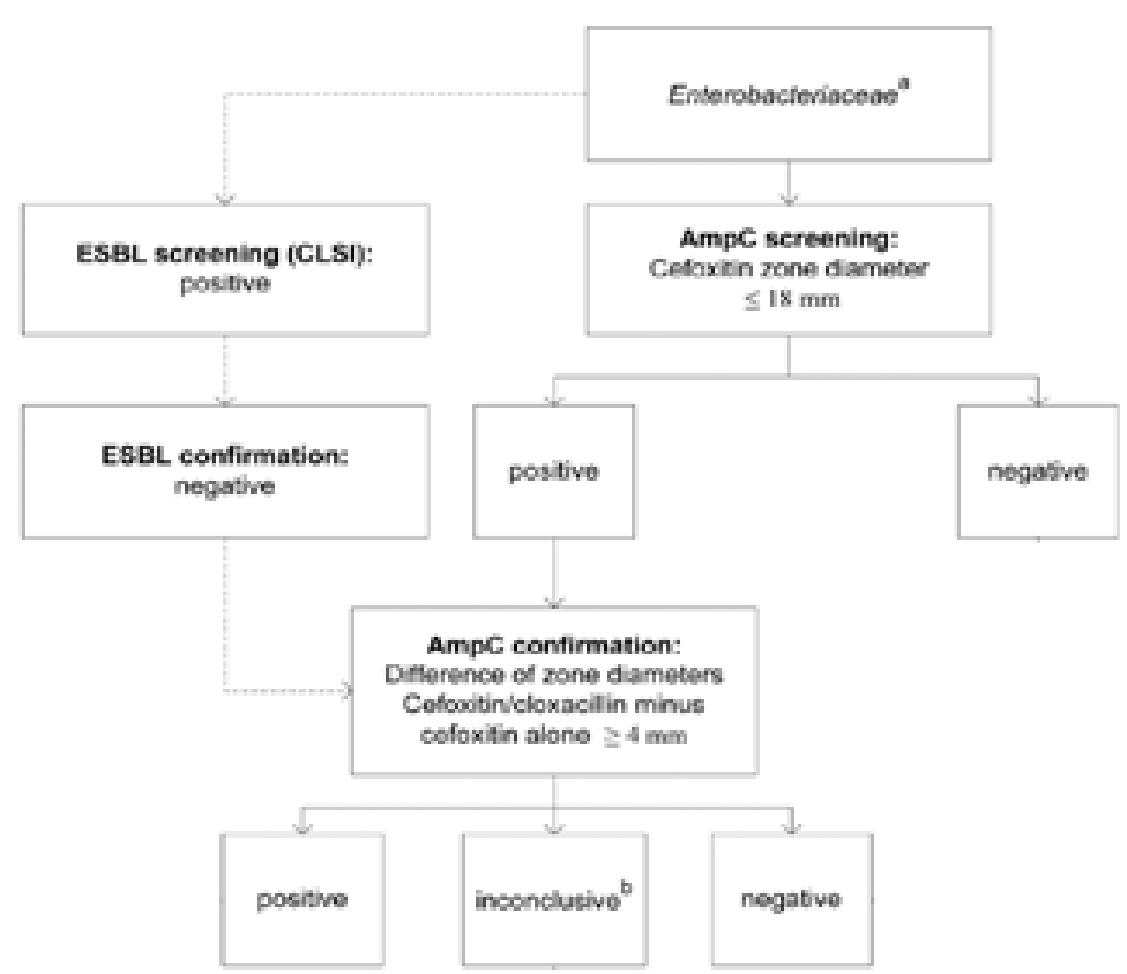

Fig. 7. Flow chart for detection of AmpC beta-lactamase production in Enterobacteriaceae. Superscript letters: a, this category includes Enterobacteriaceae spp. with no known chromosomal AmpC production plus E. coli; $b$, differences of zone diameters indicated as "inconclusive" means there were no visible inhibition zones around both cefoxitin discs with or without cloxacillin (pampC, plasmidic AmpC beta-lactamase); c, this category refers to mutations in the $\mathrm{AmpC}$ promoter region of $\mathrm{E}$. coli that result in the overexpression of AmpC. Adapted from the Journal of Clinical Microbiology (vol. 49.8 (2011): 2798-2803), by Polsfuss, Silke, et al., 2011. Copyright 2011 by the Journal of Clinical Microbiology.

Furthermore, AmpC $\beta$-lactamase detection can also be achieved using the three dimensional extract test $\mathrm{t}^{38,49,51,60}$. In this test, $50 \mathrm{mls}$ of a bacterial suspension adjusted to a $0.5 \mathrm{McF}$ arland turbidity standard prepared from an overnight culture on blood agar is inoculated into $12 \mathrm{mls}$ of tryptic soy broth ${ }^{38,49,51,60}$. Following this, the culture is grown at $350 \mathrm{C} \pm 20 \mathrm{C}$ for $4 \mathrm{hrs}{ }^{38,49,51,60}$. The bacterial cells are then centrifuged and the crude enzyme prepared by freezing-thawing the bacterial cell pellets five times $^{38,49,51,60}$. The surface of the Mueller-Hinton agar plate to be used is then inoculated with E. coli ATCC 25922 or E. coli ATCC 11775 following the standard diffusion method ${ }^{38,49,51,60}$. A commercially available cefoxitin $(30 \mu \mathrm{g})$ disc is then aseptically placed on the in- oculated agar plate ${ }^{38,49,51,60}$. A slit beginning $5 \mathrm{~mm}$ from the edge of the disc is then cut in the agar in an outward direction using a sterile scalpel blade ${ }^{49,51,60}$. Then, 25-30 mls of enzyme preparation is dispensed into the slit using a pipette, beginning near the disc and moving outwards with care being taken not to over fill the slits as shown in figure $8^{38,49,51,60}$. The inoculated media is then incubated at $35^{\circ} \mathrm{C} \pm 2^{\circ} \mathrm{C}$ for $18-24 \mathrm{hrs}^{38,49,51,60}$. Interpretation of the results is as follows: enhanced growth of the surface organism at the point where the slit intersect the zone of inhibition is reported as a positive three-dimensional extract test as seen in figure $8^{49,60,65,66}$. Testing involving swarming organisms is done on MacConkey $\operatorname{agar}^{49,51,60}$. 


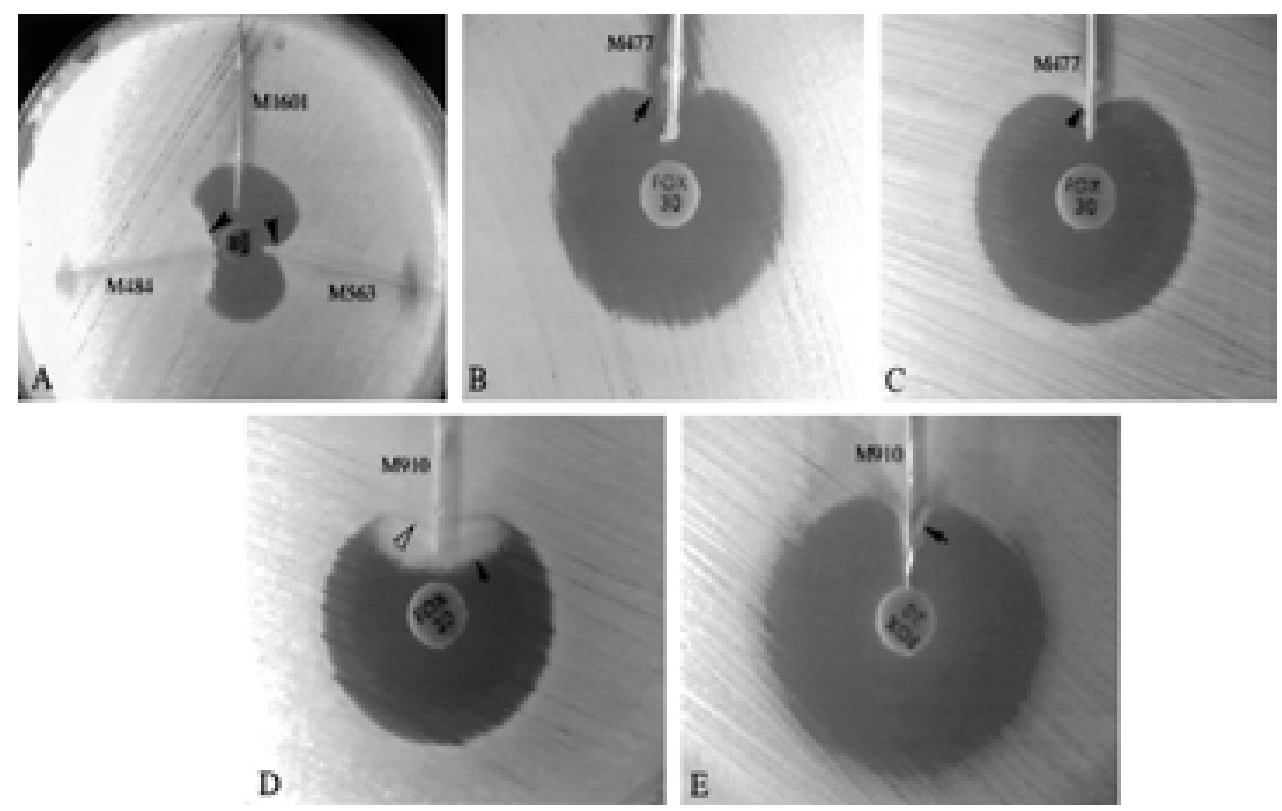

Fig. 8. Organisms showing clear distortion in the zone of inhibition: (A) enhanced growth of the surface organism, E. coli ATCC 25922 near agar slits (arrows) containing extracts of AmpC producing E. coli (M563) and K. pneumoniae (M484) test isolates. The remaining slit contained a non-AmpC-producing E. coli isolate (M1601). Extract of AmpC-producing E. coli isolate M477 inhibited the growth of one surface organism, E. coli ATCC 25922 (B) (arrow), but did not inhibit the growth of the second surface organism, $E$. coli ATCC 11775 (C) (arrow). (D) Swarming growth (dark arrow) of unlysed cells in an extract of AmpCproducing $P$. mirabilis isolate M910 interfered with detection of growth of surface organism (white arrow) when Mueller-Hinton agar was used. (E) On MacConkey agar, growth of P. mirabilis was inhibited, and enhanced growth of the surface organism was easily seen (arrow). Reprinted from the Journal of Clinical Microbiology (vol. 38(5), pp.1791-1796), by Coudron, P.E., Moland, E.S. and Thomson, K.S., 2000. Copyright 2000 by the Journal of Clinical Microbiology.

In another method, commercially available discs of

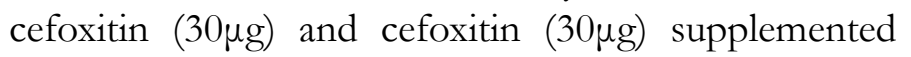
with $200 \mu \mathrm{g}$ of cloxacillin, an AmpC $\beta$-lactamase inhibitor or cefpodoxime $(10 \mu \mathrm{g})$ and cefpodoxime $(10 \mu \mathrm{g})$ supplemented with an AmpC inhibitor, either $200 \mu \mathrm{g}$ of cloxacillin or $400 \mu \mathrm{g}$ of phenylboronic acid (PBA) are used ${ }^{51,64,66-68}$. Testing using either of the options involves, inoculating a Mueller-Hinton agar plate with the test organism for the standard diffusion testing and placing a cefoxitin disc un-supplemented with an AmpC inhibitor and another cefoxitin disc supplemented with the AmpC inhibitor onto the inoculated agar plate ${ }^{50,64,66,67,69}$. This is then followed by incubation at $35^{\circ} \mathrm{C} \pm 2^{\circ} \mathrm{C}$ for $18-24 \mathrm{hrs}^{50,64,66,67,69}$. Interpretation of the results is as follows: the inhibition zone diameters in the un-supplemented cefoxitin disc and the supplemented cefoxitin disc are measured, an increase in the inhibition zone diameter in the cefoxitin disc supplemented with an AmpC inhibitor by $\geq 4 \mathrm{~mm}$ as compared to the un-supplemented disc is indicative of AmpC produc$\operatorname{tion}^{50,64,66,67,69}$.
Another method of AmpC $\beta$-lactamase detection involving the use cefoxitin $(30 \mu \mathrm{g})$ has been described ${ }^{36}$. In this test, a lawn culture of E. coli ATCC 25922 adjusted to a 0.5 McFarland standard is inoculated on Mueller-Hinton agar for standard disc diffusion testing ${ }^{36}$. Following this, a commercially available cefoxitin $(30 \mu \mathrm{g})$ disc is placed on the surface of the inoculated agar plate ${ }^{36}$. Then a sterile plain $6 \mathrm{~mm}$ paper disc initially inoculated with several colonies of the test organism is placed besides the cefoxitin disc almost making contact with it as shown in figure $9^{36}$. This is followed by incubation at $35^{\circ} \mathrm{C} \pm 2^{\circ} \mathrm{C}$ for $18-24 \mathrm{hrs}^{36}$. Interpretation is done after examination of the plates as follows: indentation or a flattening of the inhibition zone as seen in figure 9 is indicative of enzyme inactivation of the cefoxitin and is reported as a positive result whereas the absence of distortion is indicative of non-significant enzyme inactivation of the cefoxitin hence is reported as a negative result ${ }^{36}$. 


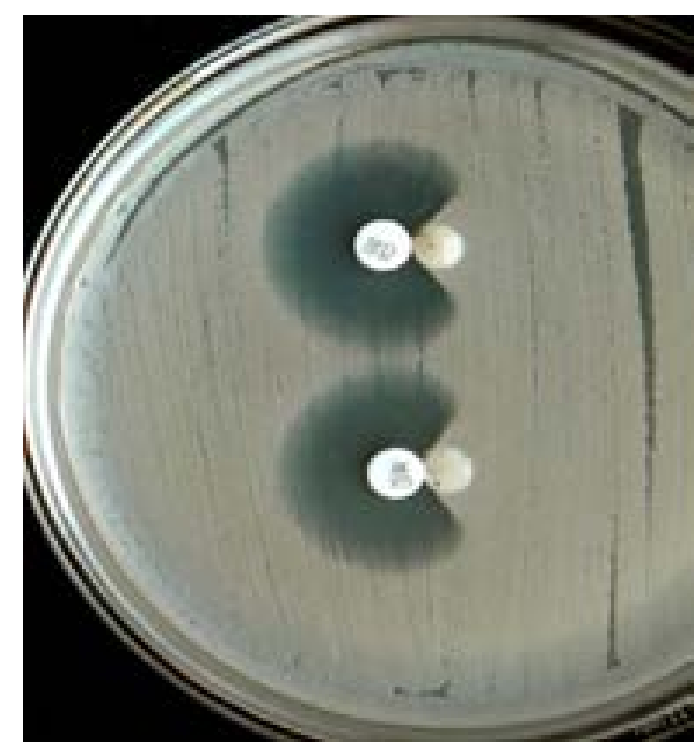

Fig. 9. Positive AmpC test shown by indentation of the zone of inhibition around cephoxitin disc. Reprinted from the Journal of Clinical and Diagnostic Research (vol. 7, 2 (2013): 229-233), by Kaur, Jaspal et al., 2013. Copyright 2013 by the Journal of Clinical and Diagnostic Research.

\section{Detection of inducible AmpC $\beta$-lactamase produc- tion}

Inducible AmpC $\beta$-lactamase activity in bacteria is detected using imipenem $(10 \mu \mathrm{g})$, cefoxitin $(30 \mu \mathrm{g})$ and amoxicillin-clavulanic acid $(20 / 10 \mu \mathrm{g})$ discs: in this testing, these are used as inducing substrates ${ }^{38,51,68,69}$. In the

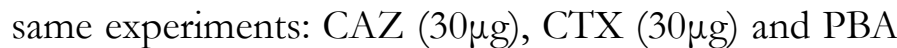
$(400 \mu \mathrm{g})$ are used as reporter substrates ${ }^{51,68,69}$. Other combinations of the inducing and reporter substrates that can be used have previously been described ${ }^{64,66,70-72}$. The discs both supplemented and the un-supplemented are placed aseptically at a distance of $20 \mathrm{~mm}$ apart, after a $0.5 \mathrm{McFarland}$ suspension of the test organism is inoculated on a Mueller-Hinton agar plate following the standard diffusion testing ${ }^{51,68,69}$. Following this, interpretation is done after the agar plate has been incubated in ambient air at $35^{\circ} \mathrm{C} \pm 2^{\circ} \mathrm{C}$ for $18-24$ hrs based on any obvious blunting or flattening of the zone of inhibition between the disc serving as the inducing substrate and the disc serving as the reporter substrate ${ }^{51,68,69}$. This observation confirms inducible AmpC $\beta$-lactamase production in the bacteria ${ }^{51,68,69}$. In the testing micro colonies present in the clear zones of inhibition are mostly ignored and measurements of inhibition zone diameters are done to the edge of the obvious inhibition ${ }^{51,68,69}$.

\section{Phenotypic detection of carbapenemase produc- tion}

Phenotypic detection of carbapenemase production in gram-negative bacteria is achieved by performing either: i) $\mathrm{MHT}^{31,61,73-76}$ or ii) mCIM, a modification of the carbapenem inactivation method (CIM) ${ }^{77,78}$. These methods have not only been documented to be simple and cost effective but have also been documented to have high sensitivity ${ }^{31,61,73-76}$. Despite the high sensitivity of MHT, it has a high frequency of false-positive results especially in carbapenem resistant Enterobacteriaceae that are producers of ESBLs and AmpC $\beta$-lactamases and low sensitivity in regards detection of NDM-1 producing bacteria ${ }^{79,80}$. In addition to this, the use of E. coli ATCC 25922 has also been implicated with low sensitivity, specificity and repeatability of MHT ${ }^{80,81}$. However, replacing E. coli ATCC 25922 with Klebsiella pneumoniae ATCC 700603 has been shown to provide high sensitivity, specificity and repeatability of the test ${ }^{81}$. MHT has also been associated with inability to discriminate between the different classes of carbapenemases (i.e. Klebsiella pneumoniae carbapenemase, Metallo $\beta$-lactamase and Oxacillinases), and difficulty in interpretation of results is reported ${ }^{82}$. Despite these, MHT remains a phenotypic reference method for confirmation of carbapenemase production ${ }^{82}$.

\section{Modified hodge test (MHT)}

The modified hodge test (MHT) is used in detection of carbapenemase production in gram-negative bacteria $^{31,49,63,73-75,83}$. In MHT, a $0.5 \mathrm{McF}$ arland dilution of E. coli ATCC 25922, an indicator strain in $5 \mathrm{ml}$ of sterile saline or nutrient broth is prepared ${ }^{31,63,73-75,83}$. The same is done for a second indicator strain, Klebsiella pneumoniae 
ATCC $700603^{31,63,73-75,83}$. Following this, a 1:10 dilution of the indicator strains is each streaked as a lawn onto a Mueller-Hinton agar plate using a sterile swab ${ }^{31,63,73-75,83}$. Then, a commercially available meropenem $(10 \mu \mathrm{g})$ or ertapenem $(10 \mu \mathrm{g})$ or imipenem $(10 \mu \mathrm{g})$ disc is placed at the center of the test area on the Mueller-Hinton agar plates $^{31,63,73-75,83,84}$. The test organism(s), positive control and negative control are then streaked in straight lines from the edge of the disc to the edge of the plate as shown in figure 10 31,63,73-75,83. Klebsiella pneumoniae ATCC BAA-1705 and Klebsiella pneumoniae ATCC-1706 are used as positive and negative controls respectively, these are ran with each batch of the test ${ }^{31,63,73-75,83}$. Incubation of the test plates is done at $35^{\circ} \mathrm{C} \pm 2^{\circ} \mathrm{C}$ for $18-24$ hrs in ambient air ${ }^{31,63,73-75,83}$. Interpretation of the tests is done after incubation as follows: the test organism(s) is positive for MHT when a clover leaf-like indentation of the E. coli ATCC 25922 or Klebsiella pneumoniae ATCC 700603 growing along the test organism growth streak within the disc diffusion zone is observed as seen in figure $10^{31,63,73-75,83}$. MHT negative organism(s) show no growth of the E. coli 25922 or Klebsiella pneumoniae ATCC 700603 along the test organism growth streak within the disk diffusion as seen in figure $10^{31,63,73-75,83}$.

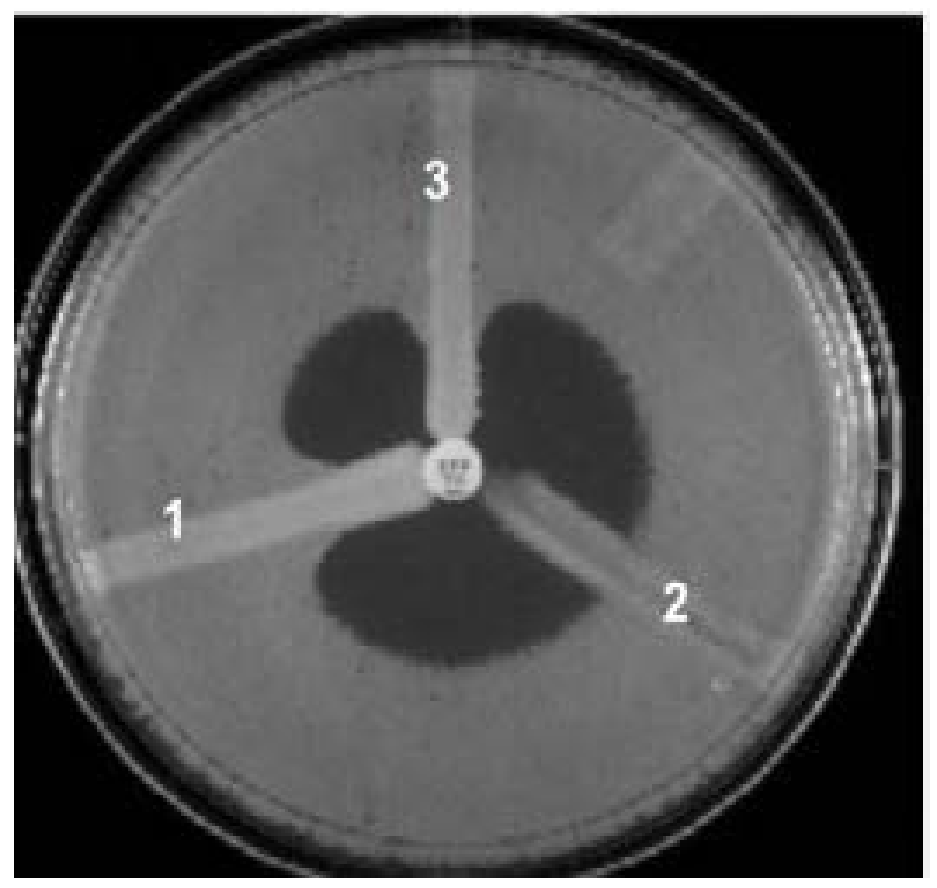

Fig. 10. MHT. (1) K. pneumoniae ATCC BAA 1705, positive result (2) K. pneumoniae ATCC BAA 1706, negative result; and (3) a clinical isolate, positive result. Reprinted from the Iranian Journal of Microbiology (vol. 3, 4 (2011): 189-193), by Amjad, A et al., 2011. Copyright 2011 by the Iranian Journal of Microbiology.

\section{Metallo $\beta$-lactamase test (MBL)}

Detection of metallo $\beta$-lactamase production in gram-negative bacteria is achieved by using two methods, namely: the imipenem-ethylene diamine tetra acetic acid, EDTA method and another double disc synergy method that involves use of a CAZ $(30 \mu \mathrm{g})$ disc and a

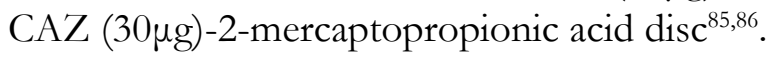

In the imipenem-EDTA method, testing is by inoculating the test organism(s) onto Mueller-Hinton agar for the standard diffusion method ${ }^{85,86}$. This is then followed by adding to the agar plates two commercially availa- ble imipenem $(10 \mu \mathrm{g})$ discs, one of the discs un-supplemented with EDTA and another supplemented with EDTA at a distance of $15 \mathrm{~mm}$ center to center as shown in figure 11; however narrower distances are associated with high test sensitivity and have been described ${ }^{85,86}$. The supplementation of the imipenem disc is done by adding $10 \mu \mathrm{l}$ of $0.5 \mathrm{M}$ EDTA to obtain the desired concentration of $1000 \mu \mathrm{g}^{74,84,85}$. A concentration of $750 \mu \mathrm{g}$ can also be used in the testing ${ }^{63,74}$. The $0.5 \mathrm{M}$ EDTA stock solution is prepared by dissolving $186.1 \mathrm{~g}$ of disodium EDTA. 2H2O in $1000 \mathrm{ml}$ of distilled wa- 
ter and adjusting the solution $\mathrm{PH}$ to 8.0 using $\mathrm{NaOH} 85$. After preparation of the mixture, it is sterilized by autoclaving $^{85}$. Incubation of the Mueller-Hinton test agar plates is done at $35^{\circ} \mathrm{C} \pm 2^{\circ} \mathrm{C}$ for $18-24 \mathrm{hrs}$ in ambient $\operatorname{air}^{85}$. These tests are interpreted after measuring the inhibition zone diameters around the imipenem disc not supplemented with EDTA and the imipenem discs supplemented with EDTA as follows: the inhibition zone diameters of the imipenem disc supplemented with
EDTA are each compared to the inhibition zone diameter of the un-supplemented imipenem disc and an increase in inhibition zone diameter of $\geq 5 \mathrm{~mm}$ in the EDTA-supplemented disc is interpreted as positive for metallo $\beta$-lactamase production ${ }^{74,84,85}$. Noteworthy, the supplemented discs prepared maybe kept at $4^{0} \mathrm{C}$ or at $-20^{\circ} \mathrm{C}$ in airtight vials without desiccant and under these conditions, these remain stable for 12 and 16 weeks respectively ${ }^{85}$.

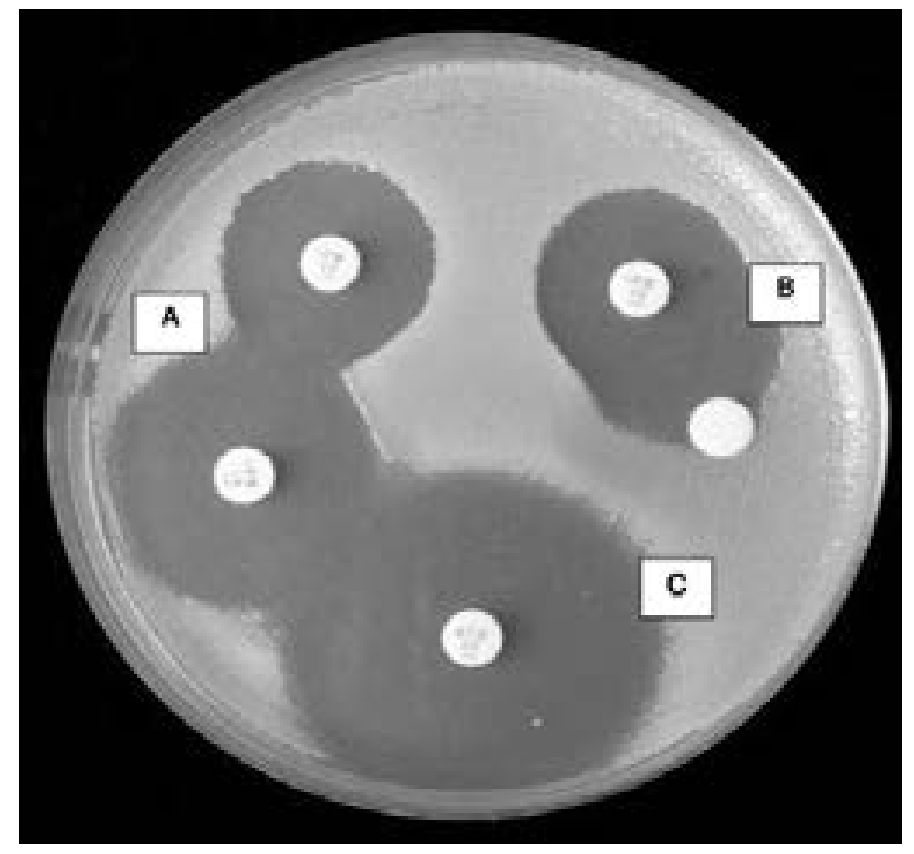

Fig. 11. The phenotypic appearance of an MBL-producing gram-negative bacteria. (A) Combineddisk test, using two imipenem (10 g) disks, one with EDTA, showing an increase in zone inhibition of $4 \mathrm{~mm}$ around the disk with EDTA. (B) Double-disk synergy test, using an IPM (10 g) disk placed $20 \mathrm{~mm}$ (center to center) from a blank filter disk containing EDTA. (C) Aztreonam (30 g) disk with a 30-mm zone of inhibition. Reprinted from the Journal of Clinical Microbiology (vol. 44(9), pp.3139-3144), by Franklin, C., Liolios, L. and Peleg, A.Y., 2006. Copyright 2011 by the Journal of Clinical Microbiology.

In the CAZ disc method, a CAZ disc and another supplemented with 2-mercaptopropionic acid are used as shown in figures 12 and $13^{85}$. In this method, the procedure and interpretation is done as documented in the previous method, the imipenem-EDTA ${ }^{85}$. 


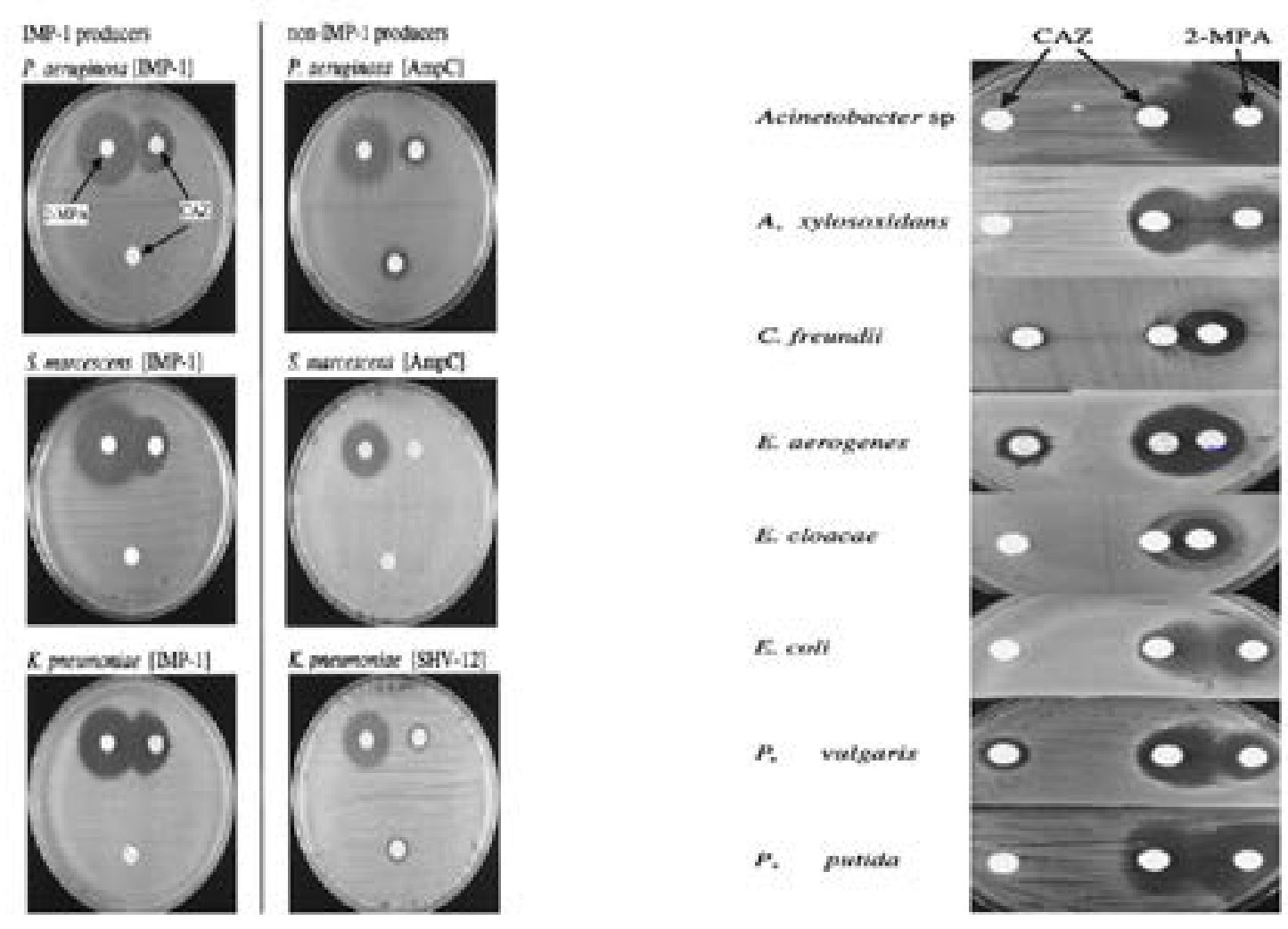

\begin{abstract}
Fig. 12. Inhibitory effects of 2-mercaptopropionic acid (2-MPA) on IMP-1 producers and non-IMP-1 producers. Three CAZ-resistant strains belonging to the gram-negative bacterial species $P$. aeruginosa, $S$. marcescens, and K. pneumoniae and producing IMP-1 metallo- $\beta$-lactamase or serine- $\beta$-lactamases (SHV12 or AmpC) were tested. For each IMP-1 producer, a distinct growth inhibitory zone appeared between the $\mathrm{KB}$ disk containing CAZ and the filter disk containing 2-MPA (left column). No change is evident around the two KB disks containing CAZ with or without 2-MPA for each serine b-lactamase producer (right column). Fig. 13. Appearance of growth-inhibitory zone in IMP-1-producing strains by use of CAZ and 2-mercaptopropionic acid (2-MPA). Various levels of growth inhibition were observed in the IMP-1producing gram-negative bacterial species tested. Marked growth inhibitions were observed in Acinetobacter sp., Alcaligenes xylosoxidans, Enterobacter aerogenes, E. coli, Proteus vulgaris, and Pseudomonas putida, whereas weak and ambiguous growth inhibitions were observed in C. freundii and $E$. cloacae. Reprinted from the Journal of Microbiology (vol. 38.1 (2000): 40-43), by Arakawa, Yoshichika, et al., 2000. Copyright 2000 by the Journal of Microbiology.
\end{abstract}

Detection of KPC, differentiation of KPC and MBL, and KPC and MBL co- production

The detection and differentiation of Klebsiella pneumoniae carbapenemase production and metallo $\beta$-lactamase production is achieved using a phenotypic algorithm that involves the use of three combined-disc tests ${ }^{7,87,88}$. These tests consist of; i) meropenem alone and meropenem supplemented with PBA, ii) meropenem alone and meropenem supplemented with ethylene diamine tetra acetic acid (EDTA), and iii) both tests ${ }^{7,87,88}$. Additionally, these tests are used to detect co-production of both carbapenemases in bacteria ${ }^{7,89}$ In these tests, the concentrations of the PBA and EDTA used are $400 \mu \mathrm{g}$ of PBA and $292 \mu \mathrm{g}$ of EDTA ${ }^{7,88}$. The stock solution of PBA is prepared by dissolving PBA in DMSO at a concentration of $20 \mathrm{mg} / \mathrm{mL}^{7,88,89}$. From this solution, $20 \mu \mathrm{l}$ (containing $400 \mu \mathrm{g}$ of PBA) are then added onto commercially available meropenem discs to obtain the PBA supplemented meropenem discs ${ }^{78,89}$. Similarly, the stock solution of EDTA is prepared by dissolving anhydrous EDTA in distilled water at a concentration of $0.1 \mathrm{M}^{7,88,89}$. From this solution, $10 \mu \mathrm{l}$ (containing $292 \mu \mathrm{g}$ 
of EDTA) are then added onto commercially available meropenem discs to obtain the EDTA supplemented meropenem discs ${ }^{7,88,89}$. Following disc preparation, the discs are dried and used within 60 minutes $^{7}$. Testing is performed by inoculating Mueller-Hinton agar for the standard diffusion method and placing onto agar plates a disc of meropenem that is not supplemented with any of the inhibitors (PBA and EDTA) and three discs of meropenem supplemented with $400 \mu \mathrm{g}$ of PBA, $292 \mu \mathrm{g}$ of EDTA or both $400 \mu \mathrm{g}$ of PBA and $292 \mu \mathrm{g}$ of EDTA as shown in figure $13^{7,88}$. Incubation of the agar plates is done at $37^{\circ} \mathrm{C}$ for $18-24 \mathrm{hrs}^{7,88,89}$. These tests are interpreted after measuring the inhibition zone diameters around the meropenem disc not supplemented with any inhibitor and the meropenem discs supplemented with either PBA, EDTA or both PBA and EDTA as follows: the inhibition zone diameters of the meropenem disc supplemented with either PBA, EDTA or both PBA and EDTA are each compared to the inhibition zone diameter of the un-supplemented meropenem disc ${ }^{7,88}$. An increase in the inhibition zone diameter in any of the supplemented meropenem discs by $\geq 5 \mathrm{~mm}$ is considered positive for Klebsiella pneumoniae carbapenemase production ${ }^{7,88}$. Bacterial isolates are considered positive for KPC and MBL co-production only when, the inhibition zone diameter around the meropenem disc supplemented with both PBA and EDTA is $\geq 5 \mathrm{~mm}$ compared to the inhibition zone diameter of the meropenem disc not supplemented with any inhibitor while the inhibition zone diameters of the meropenem disc supplemented with PBA and that supplemented with EDTA each are $\leq 5 \mathrm{~mm}$ compared to the meropenem disc not supplemented with any of the inhibitors ${ }^{7,88}$.
Detection of ESBLs in KPC producing bacteria using boronic acid based tests

Boronic acid based tests are used to detect ESBL production in KPC positive isolates ${ }^{88,89}$. In this testing, combined disc tests are used, namely: i) CTX with or without CA supplemented with PBA and ii) CAZ with or without $\mathrm{CA}$ supplemented with $\mathrm{PBA}^{88,89}$. The stock solution of PBA is prepared by dissolving PBA in DMSO and water at a concentration of $20 \mathrm{mg} / \mathrm{ml}$. From the stock solution, $20 \mu \mathrm{l}$ are added onto commercially available discs containing CTX $(30 \mu \mathrm{g})$ or CAZ $(30 \mu \mathrm{g})$ with or without CA $(10 \mu \mathrm{g})$. Addition of this volume to either of the discs makes the final volume on the discs $400 \mu \mathrm{g}{ }^{88,89}$. Following this, discs are dried and used within 60 minutes ${ }^{88}$. Testing is performed by inoculating Mueller-Hinton agar for the standard diffusion method and placing onto the agar plates a disc of CAZ or CTX with or without CA that is not supplemented with PBA and two discs of CAZ or CTX with or without CA supplemented with $400 \mu \mathrm{g}$ of PBA as shown in figure $14^{7,88}$. These tests are interpreted after measuring the inhibition zone diameters around the CAZ or CTX disc with or without CA not supplemented with BA and the CTX or CAZ disc with or without CA supplemented with BA as follows: the inhibition zone diameters of the CTX or CAZ disc with or without CA disc supplemented with $\mathrm{BA}$ are each compared to the inhibition zone diameter of the un-supplemented CTX or CAZ disc with or without $\mathrm{CA}^{88}$. An increase in the inhibition zone diameter in any of the supplemented CAZ or CTX discs with or without CA by $\geq 5 \mathrm{~mm}$ is considered positive for ESBL production ${ }^{88}$. 


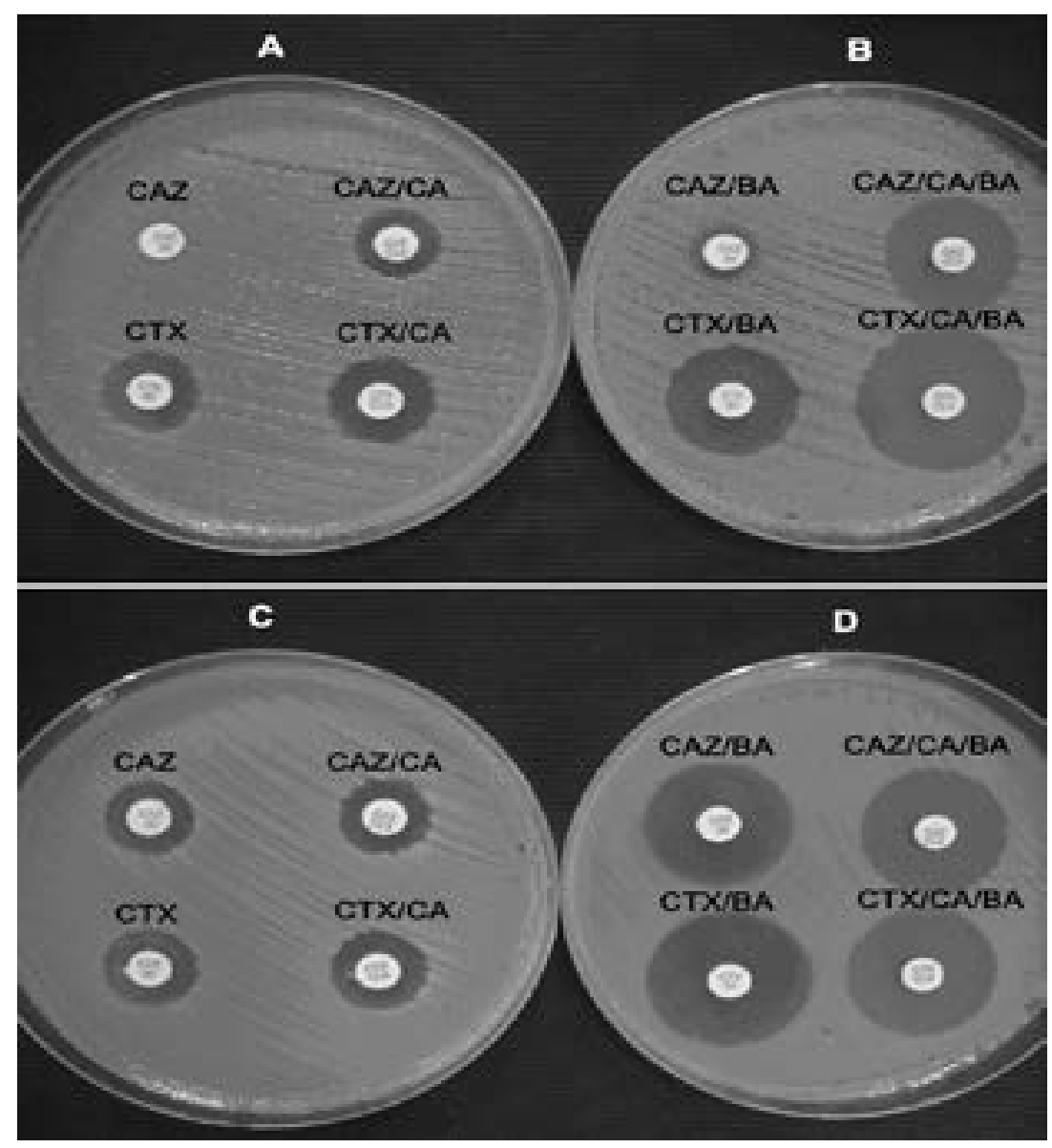

Fig. 14. Representative results of the CLSI ESBL confirmatory test (A and C) and its modification using antibiotic disks containing BA (B and D) for ESBL PCR-positive (A and B) and ESBL PCR-negative (C and D) KPC-possessing isolates. Reprinted from the Journal of Clinical Microbiology (vol. 47.11 (2009): 3420-3426), by Tsakris, Athanassios, et al., 2009. Copyright 2009 by the Journal of Clinical Microbiology.

The modified carbapenem inactivation method (mCIM)

The modified carbapenem inactivation method is a phenotypic method used in detection of carbapenemase production ${ }^{77,78}$. In this method, a sterile inoculating loop is used to add $1 \mu \mathrm{l}$ of the test organism to a tube containing $2 \mathrm{mls}$ of tryptic soy broth, following this, the bacterial suspension is then mixed by vortexing for 15 seconds $^{77,78}$. This is then followed by aseptically adding a commercially available meropenem disk $(10 \mu \mathrm{g})$ to the bacterial suspension ${ }^{77,78}$. Incubation of the bacterial suspension containing the meropenem disk is then done at $35^{\circ} \mathrm{C} \pm 2^{\circ} \mathrm{C}$ in ambient air for 4 hrs \pm 15 minutes ${ }^{77,78}$. Before completion of the incubation time, a suspension of the mCIM indicator organism, a car- bapenem susceptible Escherichia coli ATCC 25922 with a turbidity equivalent to a $0.5 \mathrm{McF}$ arland is prepared and the surface of a Mueller-Hinton agar plate is inoculated following the standard disk diffusion method and placing onto the agar plate the meropenem disc previously aseptically removed from the tryptic soy broth suspension after dragging it on the walls of the tube to drain off the excess fluid ${ }^{80,81}$. Incubation of the plate is then done at $35^{\circ} \mathrm{C} \pm 2{ }^{\circ} \mathrm{C}$ in ambient air for $18-24 \mathrm{hrs}^{77,78}$. The test is interpreted after measuring the inhibition zone diameter of the meropenem disk as follows: inhibition zone diameters of $6-10 \mathrm{~mm}$ are reported as positive for carbapenemase production, $11-19 \mathrm{~mm}$ as intermediate results and $\geq 20 \mathrm{~mm}$ as negative for carbapenemase production as shown in figures 15 and $16^{77,78}$. 


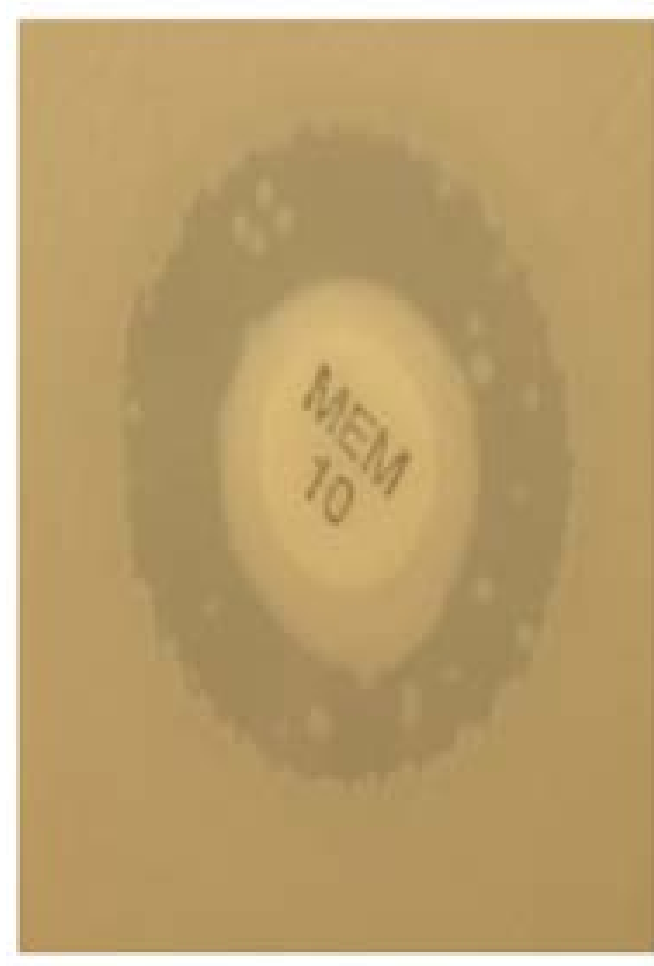

\section{A}
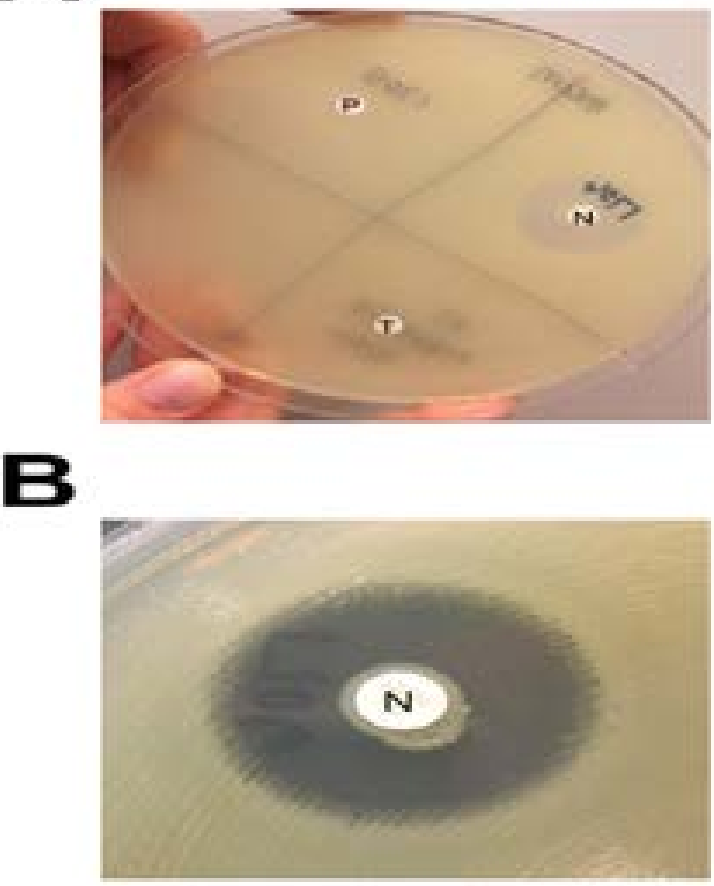

Fig. 15. Example of pinpoints within mCIM inhibition zone. During mCIM testing of some isolates, multiple small colonies could be observed growing throughout the zone of inhibition of the 10-g meropenem (MEM) disk; results are interpreted as positive when the zone of confluent growth inhibition measures $18 \mathrm{~mm}$ in diameter and as intermediate when the zone measures $19 \mathrm{~mm}$ in diameter. Fig. 16. (A and B). Reading and interpretation of mCIM results. (A) A 22-mm zone of inhibition of growth of the carbapenem-susceptible indicator organism is present around the meropenem (MEM) disk incubated with the negative-control organism $(\mathbf{N})$, while no zone of inhibition is present around the MEM disks incubated with the positive-control organism (P) or the test organism (T). (B) Closer examination of the zone around the MEM disk incubated with the negative-control organism reveals a narrow ring of growth abutting the disk, which represents carryover of the test organism from the tryptic soy broth; this growth is ignored when interpreting mCIM results. Reprinted from the Journal of Clinical Microbiology (vol. 55.8 (2017): 2321-2333), by Pierce, Virginia M., et al., 2009. Copyright 2017 by the Journal of Clinical Microbiology.

Another interpretation criteria has been previously described, in this criteria, uninhibited growth of the indicator strain is indicative of carbapenemase production whereas inhibition zone diameters of $\geq 20 \mathrm{~mm}$ are indicative of non-carbapenemase production ${ }^{77,78,90}$.

\section{Conclusion}

The review and description of previously designed phenotypic detection assays for ESBLs and carbapenemases in a single document avails a summary that allows for multiple testing which increases the sensitivity and specificity of detection. Also, extended-spectrum $\beta$-lactamase and carbapenemase detection assays when performed correctly can precisely discriminate between bacteria producing these ezymes and those with other mechanisms of resistance to $\beta$-lactam antibiotics.

\section{Declarations}

Ethical approval and consent to participate Not applicable.

\section{Consent for publication}

Not applicable.

\section{Conflicting interests}

None decalred.

\section{Author contributions}

DA, drafted, edited and reviewed both the original and final manuscripts.

\section{Acknowledgements}

Not applicable. 


\section{References}

1. Shaikh S, Fatima J, Shakil S, Rizvi SMD, Kamal MA. Antibiotic resistance and extended spectrum beta-lactamases: Types, epidemiology and treatment. Saudi J Biol Sci. 2015;22(1):90-101.

2. Sidra Shan, Saira Sajid KA. Detection of blaIMP Gene in Metallo- $\beta$-Lactamase Producing Isolates of Imipenem Resistant Pseudomonas aeruginosa; an Alarming Threat. J Microbiol Res. 2015;5(6):175-80.

3. Ambler RP. The structure of $\beta$-lactamases. Philos Trans R Soc London B, Biol Sci. 1980;289(1036):321-31.

4. Ruppé É, Woerther P-L, Barbier F. Mechanisms of antimicrobial resistance in Gram-negative bacilli. Ann Intensive Care. 2015;5(1):21.

5. Drieux L, Brossier F, Sougakoff W, Jarlier V. Phenotypic detection of extended-spectrum $\beta$-lactamase production in Enterobacteriaceae: review and bench guide. Clin Microbiol Infect. 2008;14:90-103 PubMed .

6. Steward CD, Wallace D, Hubert SK, Lawton R, Fridkin SK, Gaynes RP, et al. Ability of laboratories to detect emerging antimicrobial resistance in nosocomial pathogens: a survey of project ICARE laboratories. Diagn Microbiol Infect Dis. 2000;38(1):59-67.

7. Tsakris A, Poulou A, Pournaras S, Voulgari E, Vrioni $G$, Themeli-Digalaki $\mathrm{K}$, et al. A simple phenotypic method for the differentiation of metallo- $\beta$-lactamases and class A KPC carbapenemases in Enterobacteriaceae clinical isolates. J Antimicrob Chemother [Internet]. 2010 Aug 1;65(8):1664-71. Available from: http://dx. doi.org/10.1093/jac/dkq210

8. Testing EC on AS. Routine and extended internal quality control for MIC determination and disk diffusion as recommended by EUCAST. Version; 2019.

9. Bush K, Jacoby GA, Medeiros AA. A functional classification scheme for beta-lactamases and its correlation with molecular structure. Antimicrob Agents Chemother. 1995;39(6):1211.

10. Pfaller MA, Segreti J. Overview of the epidemiological profileand laboratory detection of extended-spectrum $\beta$-Lactamases. Clin Infect Dis. 2006;42(Supplement_4):S153-63.

11. Tzouvelekis LS, Tzelepi E, Tassios PT, Legakis NJ. CTX-M-type $\beta$-lactamases: an emerging group of extended-spectrum enzymes. Int $J$ Antimicrob Agents. 2000;14(2):137-42.

12. Bradford PA, Yang Y, Sahm D, Grope I, Gardovska D, Storch G. CTX-M-5, a Novel Cefotaxime-Hydrolyzing $\beta$-Lactamase from an Outbreak of Salmonella typhimuriumin Latvia. Antimicrob Agents Chemother. 1998;42(8):1980-4.

13. Paterson DL, Ko W-C, Von Gottberg A, Casel- las JM, Mulazimoglu L, Klugman KP, et al. Outcome of cephalosporin treatment for serious infections due to apparently susceptible organisms producing extended-spectrum $\beta$-lactamases: implications for the clinical microbiology laboratory. J Clin Microbiol. 2001;39(6):2206 PubMed -12.

14. Walsh C. Opinion-anti-infectives: where will new antibiotics come from? Nat Rev Microbiol. 2003;1(1):65.

15. Ma L, Ishii $Y$, Ishiguro $M$, Matsuzawa $H$, Yamaguchi $\mathrm{K}$. Cloning and sequencing of the gene encoding Toho2 , a class A $\beta$-lactamase preferentially inhibited by tazobactam. Antimicrob Agents Chemother. 1998;42(5):1181-6. 16. Bonnet R. Growing group of extended-spectrum $\beta$-lactamases: the CTX-M enzymes. Antimicrob Agents Chemother. 2004;48(1):1-14.

17. Sirot D, Sirot J, Labia R, Morand A, Courvalin P, Darfeuille-Michaud A, et al. Transferable resistance to third-generation cephalosporins in clinical isolates of Klebsiella pneumoniae: identification of CTX-1, a novel $\beta$-lactamase. J Antimicrob Chemother. 1987;20(3):32334.

18. Sougakoff W, Goussard S, Courvalin P. The TEM$3 \beta$-lactamase, which hydrolyzes broad-spectrum cephalosporins, is derived from the TEM-2 penicillinase by two amino acid substitutions. FEMS Microbiol Lett. 1988;56(3):343-8.

19. Livermore DM. beta-Lactamases in laboratory and clinical resistance. Clin Microbiol Rev. 1995;8(4):557-84.

20. Weldhagen GF, Poirel L, Nordmann P. Ambler class A extended-spectrum $\beta$-lactamases in Pseudomonas aeruginosa: novel developments and clinical impact. Antimicrob Agents Chemother. 2003;47(8):2385-92.

21. Neuhauser MM, Weinstein RA, Rydman R, Danziger LH, Karam G, Quinn JP. Antibiotic resistance among gram-negative bacilli in US intensive care units: implications for fluoroquinolone use. JAMA. 2003;289(7):885-8.

22. Naas T, Poirel L, Nordmann P. Minor extended-spectrum $\beta$-lactamases. Clin Microbiol Infect. 2008;14:42-52 PubMed .

23. Bradford PA. Extended-spectrum $\beta$-lactamases in the 21st century: characterization, epidemiology, and detection of this important resistance threat. Clin Microbiol Rev. 2001;14(4):933 PubMed -51.

24. Queenan AM, Bush K. Carbapenemases: the versatile $\beta$-lactamases. Clin Microbiol Rev. 2007;20(3):440-58.

25. Antunes NT, Lamoureaux TL, Toth M, Stewart NK, Frase H, Vakulenko SB. Class D ??-lactamases: Are they all carbapenemases? Antimicrob Agents Chemother. 2014;58(4).

26. Walsh TR, Toleman MA, Poirel L, Nordmann P. 
Metallo- $\beta$-Lactamases: the Quiet before the Storm? Clin Microbiol Rev [Internet]. 2005 Apr 1;18(2):306-25. Available from: http://cmr.asm.org/content/18/2/306.abstract

27. Rasmussen BA, Bush K. Carbapenem-hydrolyzing beta-lactamases. Antimicrob Agents Chemother. 1997;41(2):223.

28. Diene SM, Rolain J-M. Carbapenemase genes and genetic platforms in Gram-negative bacilli: Enterobacteriaceae, Pseudomonas and Acinetobacter species. Clin Microbiol Infect. 2014;20(9):831-8.

29. Ambler RP, Coulson AF, Frere J-M, Ghuysen J-M, Joris B, Forsman M, et al. A standard numbering scheme for the class A beta-lactamases. Biochem J. 1991;276(Pt 1):269.

30. Walsh TR. The emergence and implications of metallo- $\beta$-lactamases in Gram-negative bacteria. Clin Microbiol Infect. 2005;11:2-9 PubMed .

31. Miriagou V, Cornaglia G, Edelstein M, Galani I, Giske CG, Gniadkowski M, et al. Acquired carbapenemases in Gram-negative bacterial pathogens: detection and surveillance issues. Clin Microbiol Infect. 2010;16(2):112-22.

32. Lauretti L, Riccio ML, Mazzariol A, Cornaglia G, Amicosante G, Fontana R, et al. Cloning and characterization of bla VIM, a new integron-borne metallo- $\beta$-lactamase gene from a Pseudomonas aeruginosa clinical isolate. Antimicrob Agents Chemother. 1999;43(7):1584-90.

33. Matthew M. Plasmid-mediated $\beta$-lactamases of gram-negative bacteria: properties and distribution. $J$ Antimicrob Chemother. 1979;5(4):349-58.

34. Simpson IN, Harper PB, O'Callaghan CH. Principal beta-lactamases responsible for resistance to beta-lactam antibiotics in urinary tract infections. Antimicrob Agents Chemother. 1980;17(6):929-36.

35. Bush K. Recent developments in $\beta$-lactamase research and their implications for the future. Clin Infect Dis. 1988;10(4):681-90.

36. Jacoby GA. AmpC $\beta$-lactamases. Clin Microbiol Rev. 2009;22(1):161-82.

37. Black JA, Moland ES, Thomson KS. AmpC disk test for detection of plasmid-mediated AmpC $\beta$-lactamases in Enterobacteriaceae lacking chromosomal AmpC $\beta$-lactamases. J Clin Microbiol. 2005;43(7):3110-3. 38. Philippon A, Arlet G, Jacoby GA. Plasmid-determined AmpC-type $\beta$-lactamases. Antimicrob Agents Chemother. 2002;46(1):1-11.

39. Oberoi L, Singh N, Sharma P, Aggarwal A. ESBL, MBL and Ampc $\beta$ lactamases producing superbugs-
Havoc in the Intensive Care Units of Punjab India. J Clin diagnostic Res JCDR. 2013;7(1):70.

40. Singhal S, Mathur T, Khan S, Upadhyay DJ, Chugh $\mathrm{S}$, Gaind R, et al. Evaluation of methods for AmpC beta-lactamase in gram negative clinical isolates from tertiary care hospitals. Indian J Med Microbiol. 2005;23(2):120. 41. Shoorashetty RM, Nagarathnamma T, Prathibha J. Comparison of the boronic acid disk potentiation test and cefepime-clavulanic acid method for the detection of ESBL among AmpC-producing Enterobacteriaceae. Indian J Med Microbiol. 2011;29(3):297.

42. Hageman JC, Fridkin SK, Mohammed JM, Steward CD, Gaynes RP, Tenover FC. Antimicrobial proficiency testing of National Nosocomial Infections Surveillance System hospital laboratories. Infect Control Hosp Epidemiol. 2003;24(5):356-61.

43. Tenover FC, Mohammed MJ, Stelling J, O’Brien T WR. Ability of laboratories to detect emerging antimicrobial resistance: proficiency testing and quality control results from the World Health Organization's external quality assurance system for antimicrobial susceptibility testing. J Clin Microbiol. 2001;39((1)):241-50. 44. Pitout JD, Nordmann P, Laupland KB PL. Emergence of Enterobacteriaceae producing extendedspectrum $\beta$-lactamases (ESBLs) in the community. J Antimicrob Chemother. 2005;56((1)):52-59.

45. Stevenson KB, Samore M, Barbera J, Moore JW, Hannah E, Houck P, et al. Detection of antimicrobial resistance by small rural hospital microbiology laboratories: comparison of survey responses with current NCCLS laboratory standards. Diagn Microbiol Infect Dis. 2003;47(1):303-11.

46. Grover N, Sahni AK, Retd SB. Therapeutic challenges of ESBLS and AmpC beta-lactamase producers in a tertiary care center. Med J Armed Forces India. 2013;69(1):4-10.

47. Queenan AM, Foleno B, Gownley C, Wira E, Bush $K$. Effects of inoculum and $\beta$-lactamase activity in Am$\mathrm{pC}$-and extended-spectrum $\beta$-lactamase (ESBL)-producing Escherichia coli and Klebsiella pneumoniae clinical isolates tested by using NCCLS ESBL methodology. J Clin Microbiol. 2004;42(1):269-75.

48. Willems E, Verhaegen J, Magerman K, Nys S, Cartuyvels $\mathrm{R}$. Towards a phenotypic screening strategy for emerging $\beta$-lactamases in Gram-negative bacilli. Int $J$ Antimicrob Agents. 2013;41(2):99-109.

49. Legrand P, Fournier G, Bure A, Jarlier V, Nicolas MH, Decre D, et al. Detection of extended broad-spectrum beta-lactamases inEnterobacteriaceae in four French hospitals. Eur J Clin Microbiol Infect Dis. 1989;8(6):527-9. 
50. M'Zali FH, Chanawong A, Kerr KG, Birkenhead D, Hawkey PM. Detection of extended-spectrum $\beta$-lactamases in members of the family Enterobacteriaceae: comparison of the MAST DD test, the double disc and the Etest ESBL. J Antimicrob Chemother. 2000;45(6):8815.

51. Thomson KS, Sanders CC. Detection of extended-spectrum beta-lactamases in members of the family Enterobacteriaceae: comparison of the double-disk and three-dimensional tests. Antimicrob Agents Chemother. 1992;36(9):1877-82.

52. Rawat D, Nair D. Extended-spectrum $\beta$-lactamases in Gram Negative Bacteria. J Glob Infect Dis. 2010;2(3):263.

53. (CLSI) C and LSI. Performance Standards for Antimicrobial Susceptibility Testing. CLSI supplement M100. Clinical and Laboratory Standards, 2018. $28^{\text {th }}$ ed. 2018; (28 ${ }^{\text {th }}$ ed.).

54. Livermore DM, Paterson DL. Pocket guide to extended-spectrum $\beta$-lactamases in resistance. Current Medicine Group; 2006.

55. Steward CD, Biddle JW, Raney PM, Anderson GJ. Characterization of clinical isolates of Klebsiella pneumoniae from 19 laboratories using the NCCLS extended-spectrum betalactamase detection methods. J Clin Microbiol. 2001;39:2864-72 PubMed .

56. Jarlier V, Nicolas M-H, Fournier G, Philippon A. Extended broad-spectrum $\beta$-lactamases conferring transferable resistance to newer $\beta$-lactam agents in Enterobacteriaceae: hospital prevalence and susceptibility patterns. Clin Infect Dis. 1988;10(4):867 PubMed -78.

57. Kaur J, Chopra S, Sheevani GM. Modified double disc synergy test to detect ESBL production in urinary isolates of Escherichia coli and Klebsiella pneumoniae. J Clin diagnostic Res JCDR. 2013;7(2):229.

58. Garrec H, Drieux-Rouzet L, Golmard J-L, Jarlier V, Robert J. Comparison of nine phenotypic methods for detection of extended-spectrum $\beta$-lactamase production by Enterobacteriaceae. J Clin Microbiol. 2011;49(3):1048 PubMed -57.

59. Pitout JDD, Laupland KB. Extended-spectrum $\beta$-lactamase-producing Enterobacteriaceae: an emerging public-health concern. Lancet Infect Dis. 2008;8(3):159 PubMed -66.

60. Tzelepi E, Giakkoupi P, Sofianou D, Loukova V, Kemeroglou A, Tsakris A. Detection of Extended-Spectrum $\beta$-Lactamases in Clinical Isolates of Enterobacter cloacae andEnterobacter aerogenes. J Clin Microbiol. 2000;38(2):542 PubMed -6.

61. Hemalatha V, Padma M, Sekar U, Vinodh TM, Arunkumar AS. Detection of Amp C beta lactamases production in Escherichia coli \& Klebsiella by an inhibitor based method. Indian J Med Res. 2007;126(3):220 PubMed.

62. El-Hady SA, Adel LA. Occurrence and detection of AmpC $\$ \beta \$$-lactamases among Enterobacteriaceae isolates from patients at Ain Shams University Hospital. Egypt J Med Hum Genet. 2015;16(3):239-44.

63. Brenwald NP, Jevons G, Andrews J, Ang L, Fraise AP. Disc methods for detecting AmpC $\beta$-lactamase-producing clinical isolates of Escherichia coli and Klebsiella pneumoniae. J Antimicrob Chemother. 2005;56(3):600-1. 64. Ingram PR, Inglis TJJ, Vanzetti TR, Henderson BA, Harnett GB, Murray RJ. Comparison of methods for AmpC $\beta$-lactamase detection in Enterobacteriaceae. $J$ Med Microbiol. 2011;60(6):715-21.

65. Coudron PE, Moland ES, Thomson KS. Occurrence and detection of $\mathrm{AmpC}$ beta-lactamases among Escherichia coli, Klebsiella pneumoniae, and Proteus mirabilis isolates at a veterans medical center. J Clin Microbiol. 2000;38(5):1791-6.

66. Tan TY, Ng LSY, He J, Koh TH, Hsu LY. Evaluation of screening methods to detect plasmid-mediated AmpC in Escherichia coli, Klebsiella pneumoniae, and Proteus mirabilis. Antimicrob Agents Chemother. 2009;53(1):146-9.

67. Vercauteren E, Descheemaeker P, Ieven M, Sanders CC, Goossens H. Comparison of screening methods for detection of extended-spectrum beta-lactamases and their prevalence among blood isolates of Escherichia coli and Klebsiella spp. in a Belgian teaching hospital. J Clin Microbiol. 1997;35(9):2191-7.

68. M'Zali FH, Heritage J, Gascoyne-Binzi DM, Denton M, Todd NJ, Hawkey PM. Transcontinental importation into the UK of Escherichia coli expressing a plasmid-mediated AmpC-type beta-lactamase exposed during an outbreak of SHV-5 extended-spectrum beta-lactamase in a Leeds hospital. I Antimicrob Chemother. 1997;40(6):823-31.

69. Peter-Getzlaff S, Polsfuss S, Poledica M, Hombach M, Giger J, Böttger EC, et al. Detection of AmpC beta-lactamase in Escherichia coli: comparison of three phenotypic confirmation assays and genetic analysis. $J$ Clin Microbiol. 2011;49(8):2924-32.

70. Coudron PE. Inhibitor-based methods for detection of plasmid-mediated AmpC $\beta$-lactamases in Klebsiella spp., Escherichia coli, and Proteus mirabilis. J Clin Microbiol. 2005;43(8):4163-7.

71. Polsfuss S, Bloemberg G V, Giger J, Meyer V, Böttger EC, Hombach M. Practical approach for reliable detection of AmpC beta-lactamase-producing Enterobacteriaceae. J Clin Microbiol. 2011;49(8):2798-803. 
72. Yagi T, Wachino J, Kurokawa H, Suzuki S, Yamane K, Doi Y, et al. Practical methods using boronic acid compounds for identification of class $C \beta$-lactamase-producing Klebsiella pneumoniae and Escherichia coli. J Clin Microbiol. 2005;43(6):2551-8.

73. Amjad A, Mirza IA, Abbasi SA, Farwa U, Malik N, Zia F. Modified Hodge test: A simple and effective test for detection of carbapenemase production. Iran J Microbiol. 2011;3(4):189.

74. Kateete DP, Nakanjako R, Namugenyi J, Erume J, Joloba ML, Najjuka CF. Carbapenem resistant Pseudomonas aeruginosa and Acinetobacter baumannii at Mulago Hospital in Kampala, Uganda (2007-2009). Springerplus [Internet]. 2016 Aug 9;5(1):1308. Available from: http://www.ncbi.nlm.nih.gov/pmc/articles/ PMC4978656/

75. Okoche D, Asiimwe BB, Katabazi FA, Kato L, Najjuka CF. Prevalence and Characterization of Carbapenem-Resistant Enterobacteriaceae Isolated from Mulago National Referral Hospital, Uganda. PLoS One [Internet]. 2015 Aug 18;10(8):e0135745. Available from: https://doi.org/10.1371/journal.pone.0135745

76. Asthana S, Mathur P, Tak V. Detection of carbapenemase production in Gram-negative bacteria. J Lab Physicians. 2014;6(2):69.

77. Pierce VM, Simner PJ, Lonsway DR, Roe-Carpenter DE, Johnson JK, Brasso WB, et al. Modified carbapenem inactivation method for phenotypic detection of carbapenemase production among Enterobacteriaceae. J Clin Microbiol. 2017;55(8):2321-33.

78. van der Zwaluw K, de Haan A, Pluister GN, Bootsma HJ, de Neeling AJ, Schouls LM. The carbapenem inactivation method (CIM), a simple and low-cost alternative for the Carba NP test to assess phenotypic carbapenemase activity in gram-negative rods. PLoS One. 2015;10(3):e0123690.

79. Hrabák J, Chudáčková E, Papagiannitsis CC. Detection of carbapenemases in Enterobacteriaceae: a challenge for diagnostic microbiological laboratories. Clin Microbiol Infect. 2014;20(9):839-53.

80. Pasteran F, Mendez T, Rapoport M, Guerriero L, Corso A. Controlling false-positive results obtained with the Hodge and Masuda assays for detection of class A carbapenemase in species of Enterobacteriaceae by incorporating boronic acid. J Clin Microbiol. 2010;48(4):1323-32.

81. Pasteran F, Veliz O, Rapoport M, Guerriero L, Cor- so A. Sensitive and specific modified Hodge test for KPC and metallo-beta-lactamase detection in Pseudomonas aeruginosa by use of a novel indicator strain, Klebsiella pneumoniae ATCC 700603. J Clin Microbiol. 2011;49(12):4301-3.

82. Bialvaei AZ, Kafil HS, Asgharzadeh M, Yousef Memar M, Yousefi M. Current methods for the identification of carbapenemases. J Chemother. 2016;28(1):1-19.

83. Tenover FC, Emery SL, Spiegel CA, Bradford PA, Eells S, Endimiani A, et al. Identification of plasmid-mediated AmpC $\beta$-lactamases in Escherichia coli, Klebsiella spp., and Proteus species can potentially improve reporting of cephalosporin susceptibility testing results. J Clin Microbiol. 2009;47(2):294-9.

84. Asthana S, Mathur P T V. Detection of carbapenemase production in Gram-negative bacteria. J Lab Physicians. 2014;6(2)(69-75).

85. Yong D, Lee K, Yum JH, Shin HB, Rossolini GM, Chong Y. Imipenem-EDTA disk method for differentiation of metallo- $\beta$-lactamase-producing clinical isolates of Pseudomonas spp. and Acinetobacter spp. J Clin Microbiol. 2002;40(10):3798-801.

86. Arakawa Y, Shibata N, Shibayama K, Kurokawa $H$, Yagi T, Fujiwara $H$, et al. Convenient test for screening metallo- $\beta$-lactamase-producing gram-negative bacteria by using thiol compounds. J Clin Microbiol. 2000;38(1):40-3.

87. Song W, Bae IK, Lee Y-N, Lee C-H, Lee SH, Jeong $\mathrm{SH}$. Detection of extended-spectrum $\beta$-lactamases by using boronic acid as an AmpC $\beta$-lactamase inhibitor in clinical isolates of Klebsiella spp. and Escherichia coli. J Clin Microbiol. 2007;45(4):1180-4.

88. Tsakris A, Poulou A, Themeli-Digalaki K, Voulgari E, Pittaras T, Sofianou D, et al. Use of boronic acid disk tests to detect extended-spectrum $\beta$-lactamases in clinical isolates of KPC carbapenemase-possessing Enterobacteriaceae. J Clin Microbiol. 2009;47(11):3420-6.

89. Pournaras S, Poulou A, Tsakris A. Inhibitor-based methods for the detection of KPC carbapenemase-producing Enterobacteriaceae in clinical practice by using boronic acid compounds. I Antimicrob Chemother [Internet]. 2010 Jul 1;65(7):1319-21. Available from: http:/ / dx.doi.org/10.1093/jac/dkq124

90. Tijet N, Patel SN, Melano RG. Detection of carbapenemase activity in Enterobacteriaceae: comparison of the carbapenem inactivation method versus the Carba NP test. J Antimicrob Chemother. 2015;71(1):274-6. 